\title{
ARCHITECTURE WITHOUT ARCHITECTS
}

\author{
A Thesis \\ Presented to \\ The Faculty of the Department of Architecture \\ Cornell University \\ In fulfillment \\ of the Requirements for the Degree of \\ Master of Science in Advance Architectural Design
}

by

Hansen Sentosa

May, 2020 
This portfolio is a manifestation of an ongoing investigation of understanding the agency of architecture in our current built environment. Through illustrations and writings, I elaborated my research and understanding of architecture in the area of my TI (Territory of Investigation) Architecture and Discourse. It mainly consists of two different studio explorations (ARCH 7712 - Rational Form Making) (ARCH 7113 - Universum Carrousel Journey), and elective courseworks related to my Territory of Investigations (ARCH 6308 - Shinohara Kazuo and Contemporary Arch in Japan) (ARCH 6408 - Robots, Cyborgs, and Architecture) (ARCH 6408 PhotoArch/Collective Fictions) (ARCH 6309 - Principles, Theories, and Elements in Japanese Architecture and Gardens). In the research, I attempt to challenge the idealistic role of architects in defining the future of our built environment. With the advancement of technology, methods of building, and materials in this postmodernism era, certain changes, inventions, and evolution of styles are inevitable. The title "Architecture Without Architects" summarizes the modern trend where the essence of architecture is often neglected and overcome by aesthetic, ego, and power. A phenomenon that leads us to the question of "to what degree is the role of vernacular architecture transpiring in this 21 st century, when glass and steel towers proliferate and the homogeneity of urban fabric increases?" Therefore, in this research I would like to explore how architects can adopt the essence of vernacular architecture while still maintaining the integrity and aspects of post-modern architecture. The research is concluded with comprehensive illustrations and supplemental materials of my work to support the respective investigation. 
Table of Contents

Research Paper (Architecture Without Architects)

Archive (ARCH 7712 - Rational Form Making)

Archive (ARCH 7113 - Universum Carrousel Journey)

Archive (ARCH 6408 - Summer, Territory of Investigation) 
With the advancement of technology, methods of building, and materials in this

What I have learnt about architecture these passing years has raised my curiosity and interest in the idealistic role of architects in defining the future of our society. In the 21st century, I realize the challenge we are facing is the eroding quality of our general built environment. In Hong Kong, for example, high-rises were built with minimal set-back in the city fabric, creating extreme density and causing urban congestion. For architecture to regain its foothold as a substantive medium, the general quality of the built environment needs to be raised to a much higher level. In this technology - saturated age, when prefabrication becomes the new norm of construction, skyscrapers and high-rise buildings have become a prominent measure of modern cities. To say the least, we are confronted with the syndrome of "city anonymity". What makes a building complex in New York different from one in Shanghai, or Chicago, Hong Kong, and Tokyo? All these cities have accumulated a tremendous sprout of "concrete jungle" portraying power and capitalism, bold and conflicting to the environment. This sequence: the accumulation of modernist ideals, the imagery of our discipline's failure, and our inability to recover from such a fall, has culminated in the marginalization of our professional and cultural authority. As a consequence, we indulged ourselves in solving this self-created problem.

For architecture to regain its relevance, it must perform outside of its prescribed role by curating techniques and modalities of thought that establish extrinsic relevance in service of repositioning ourselves as authoritative guardians of the environment and culture. While many obsess over the rapid growth that leads to a monochromatic scheme of a city, an architecture which presents a new perspective on such a built environment becomes essential in a time that views the loss of identity as imminent. In response, I believe revitalizing vernacular architecture is crucial to fight the paradigm shift from local to global in the realm of architecture. postmodernism era, certain changes, inventions, and evolution of styles are inevitable. A movemen that leads us to the question of "to what degree is the role of vernacular architecture transpiring in this 21 st century, when glass and steel towers proliferate and the homogeneity of urban fabric increases?" Therefore, in this research I would like to explore how architects can adopt the essence of vernacular architecture while still maintaining the integrity and aspects of post-modern architecture.

In the global era, when homogenous architectural styles have infiltrated the urban fabric of cities around the world, architects ought to seek solutions to prevent this accumulation of urban concrete and the eroding culture of our society. Sendai Mediatheque, being one of the most notable architecture pieces in the 21st century, stands as an exemplary work that displays the unification of vernacular and post-modern architecture. Despite its modern look and advance physics, Sendai Mediatheque has taken inspiration from native Japanese tree, Zelkova, an ornamental tree with seemingly weaving trunks, and traditional "tree-like" structure that can be traced back to the 592 710 Asuka period in the history of Japanese architecture from Horyu-ji Temple. The columns on Sendai Mediatheque work identically with that of Horyu-ji Pagoda, with a technique called 'tuned mass damping, where the architects let the columns (Shinbashira) move deliberately to withstand shear forces from wind and earthquake.

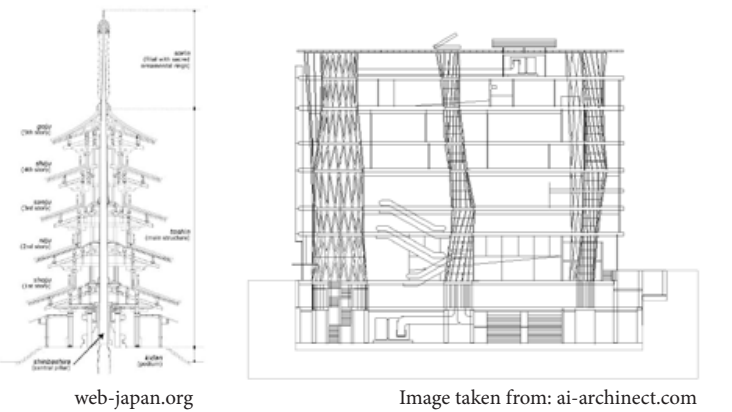

"Sendai Mediatheque survived a devastating magnitude 9.0 earthquake in 2011. The image indicates how Toyo Ito balance and structural efficiency, one that could withstand such natural forces. Two points to be noted here are as follow: (1) the columns start from the underground, giving a higher tolerance for the columns to shear. (2) Dynamic (higher tolerance) rectangular structure is located below the rigid (less tolerance) triangular structure, increasing the tolerance 
The research continued with an exploration in combining different, possibly contradictory, existing architecture concepts, including Sendai Mediatheque, Mannheim Multihalle, Orleans Bridge, and Millennium Dome, in order to come up with an innovative piece of architecture. It is an attempt to showcase architecture as a growing and evolving process, as we have 'stood on the shoulders of giants' to reach this point today. Hereby, the final outcome of the exploration was formed through one iteration after another, a methodology used to preserve fragments of architecture and move forward.

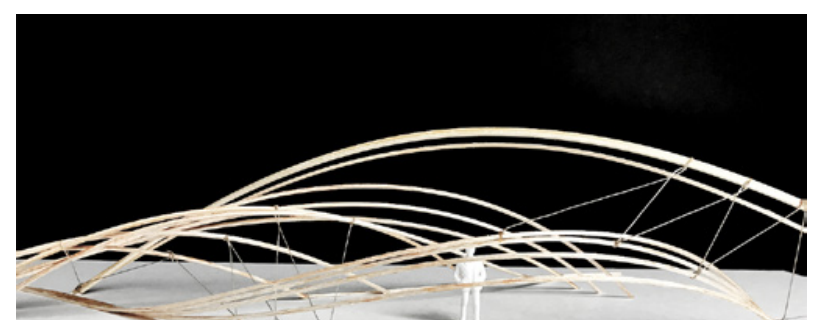

To understand further about the application of vernacular architecture in the postmodernism setting, a research on five different exemplary houses throughout three different cultures, America, Japan, and Europe was conducted. The case studies focused on the architecture history, typology, and tradition of each respective house and how they can relate to one another. These houses were made by architects Yoshida Isoya, Kazuo Shinohara, Jos Van Driessche, and the architect of the Shaker House, pioneers of their respective era. The study began with Inomata-tei, by Yoshida Isoya, a Japanese architect and pioneer of modern 'sukiya style' of building, in which an affinity for natural materials and traditional construction techniques finds expression in contemporary structures. According to Yoshida Isoya, a 'sukiya style', although ordinarily based on handcrafting in wood, could use modern materials as long as they were used in the 'spirit of the style. This expression could be seen in Inomata-tei, 1967, where he altered the traditional style of japanese architecture into a modern setting
A study of House in Uehara, by Kazuo Shinohara, is crucial to understand how vernacular architecture (in Japan) evolved during the transitional era of globalization. As Japan's most celebrated postwar architect, Kazuo Shinohara had initiated an empirical research into Japan’s contemporary vernacular architecture and the typology of private houses where he separated his findings into four different styles each with its time period. For example, House in Uehara, 1976, would fall into the 'third style' of his architectural language.

Van driessche house, 1980, is a derivation of several architecture pieces one of which is Frank Lloyd Wright's FallingWater. The impact of Scandinavian architecture was clearly visible in his architectural designs in a kind of 'romantic modernism', in which he established an organic connection between architecture and relief design. As a Belgian pioneer in architecture, Jos Van Driessche has established his place among the notable architects in his era.

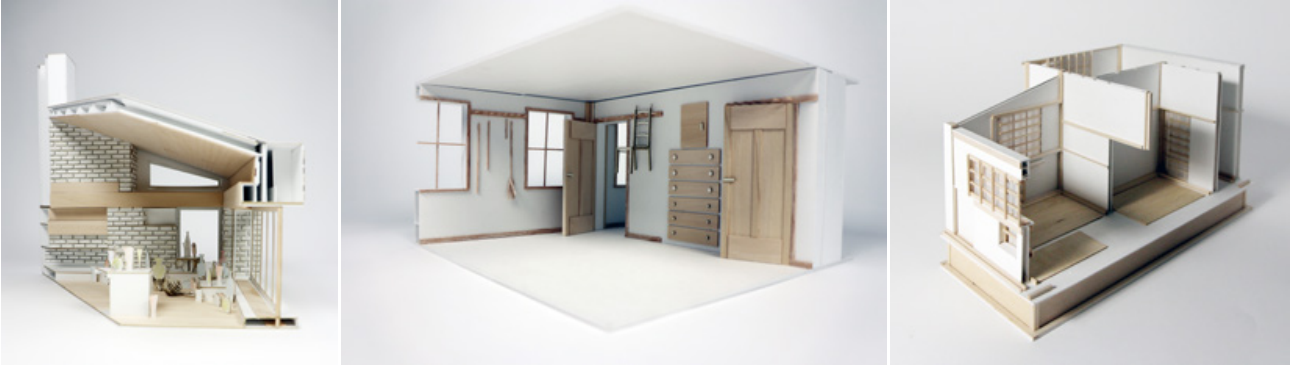

These studies aimed to understand the relation between the making (construction), material and detail, the meaning (context), culture, and tradition. Using this methodology is a way to preserve our history and to move forward in creating new architecture. The study continued with creating several iterations as an attempt to merge several congruent elements of those different houses together. I concluded the research and studies by showcasing transcription pieces of architecture throughout history in the form of a house, an effort to show the possibility of adopting the essence of vernacular architecture in a post-modern architecture setting. 
It is very unfortunate that vernacular architecture tends to be overlooked in the era of globalization, where most architecture are bound by money and power as sole inspiration. Nowadays, we often see stylistic elements of design intentionally incorporated for aesthetic purposes which go beyond a building's functional requirements. On one hand, it allows architects to create astonishing, extravagant, sculpture-like pieces of architecture. On the other hand however, the atmosphere, the sense of place, and the essence of architecture are often neglected, leading to the diminishing quality of our built environment. To end this phenomenon, I found it necessary to analyze the context, studying the cultural, social, and artistic influences of architecture pieces before going into the drawing board. We ought to let ourselves be inspired by architectural works in the past and carry on the concept of those pieces to the current. Vernacular architecture should be the key element to our progression in this post-modern era. Hence, it is up to the new generation of architects to question the status quo. 


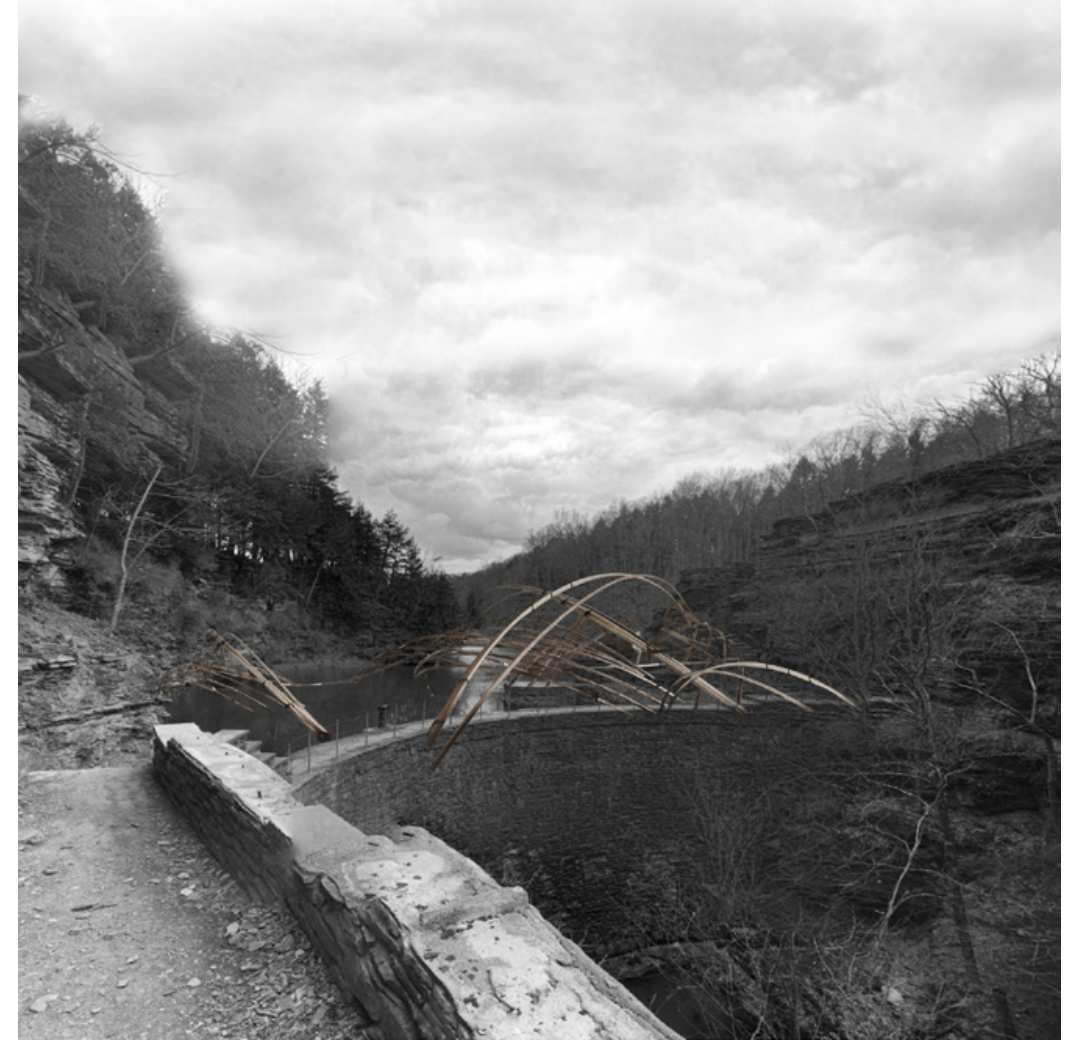

Exterior Render

Digital media: V-ray raw render, Photoshop

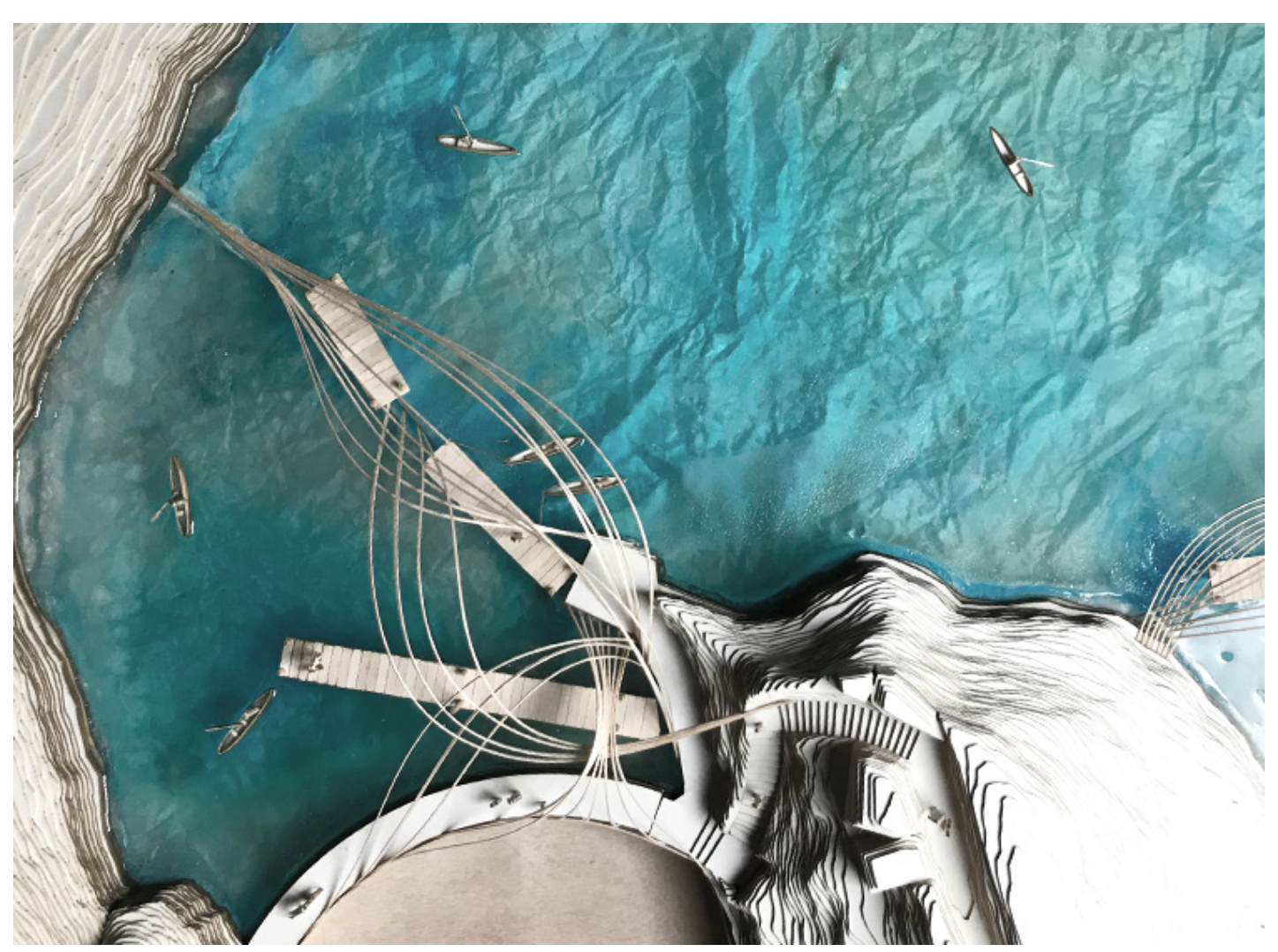

Physical Model (20" x 24" x 8")

Media: 1/16" matboard, 1/16" balsa, $1 / 32$ " wood dowel, resin 

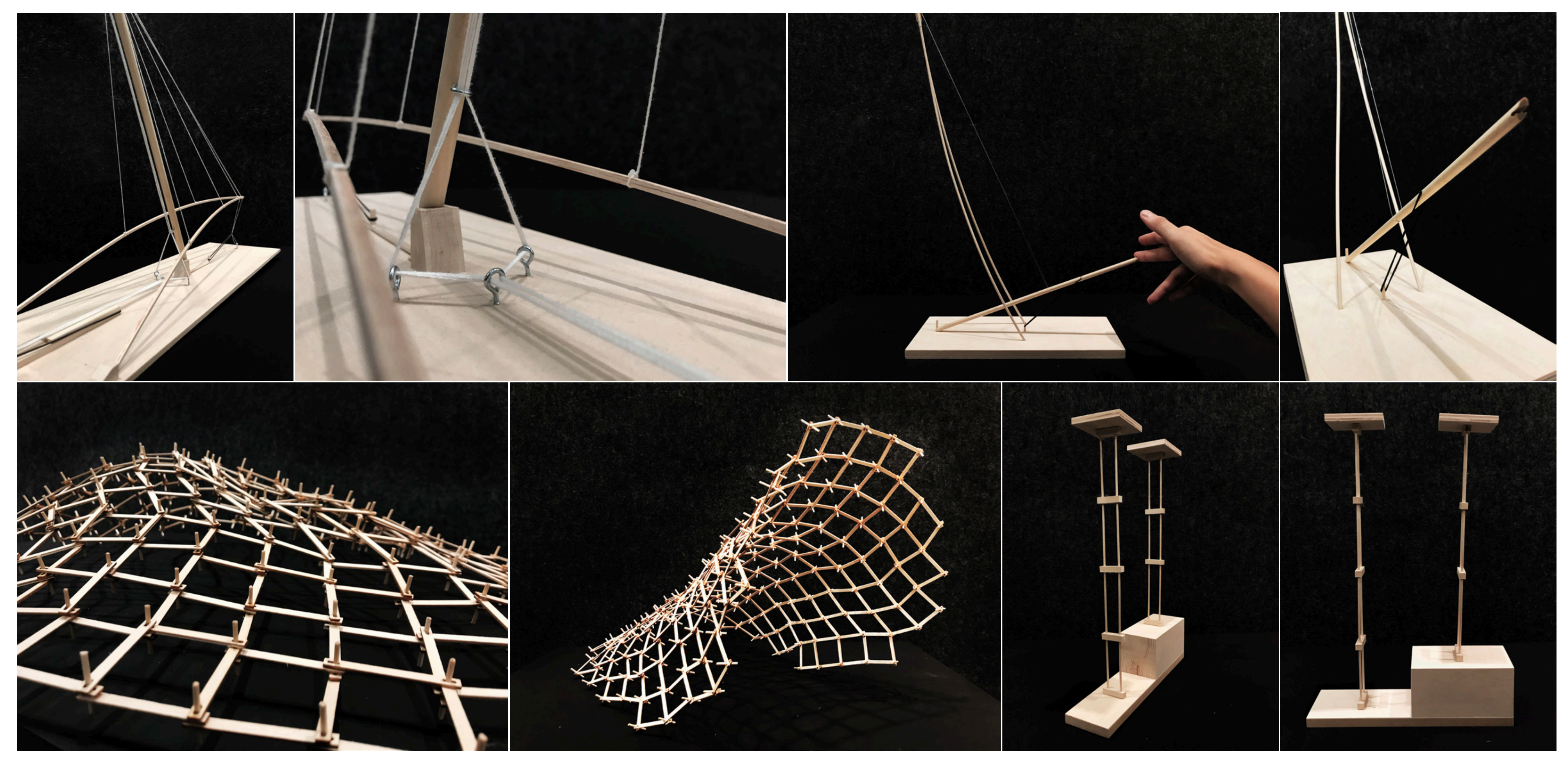

Case studies of different architectural project Sendai Mediatheque

Mannheim Multihalle

Millennium Dome Orleans Bridge 
RATIONAL EORM MAKING
\#STRUCTRRLL RATIONALISM

Typology: Pavilion
Location: Lake Treman / Ithaca / NY

Instructor: Angela Pang
Work Tye: Independent Study

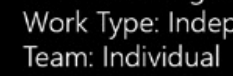

Fall 2019

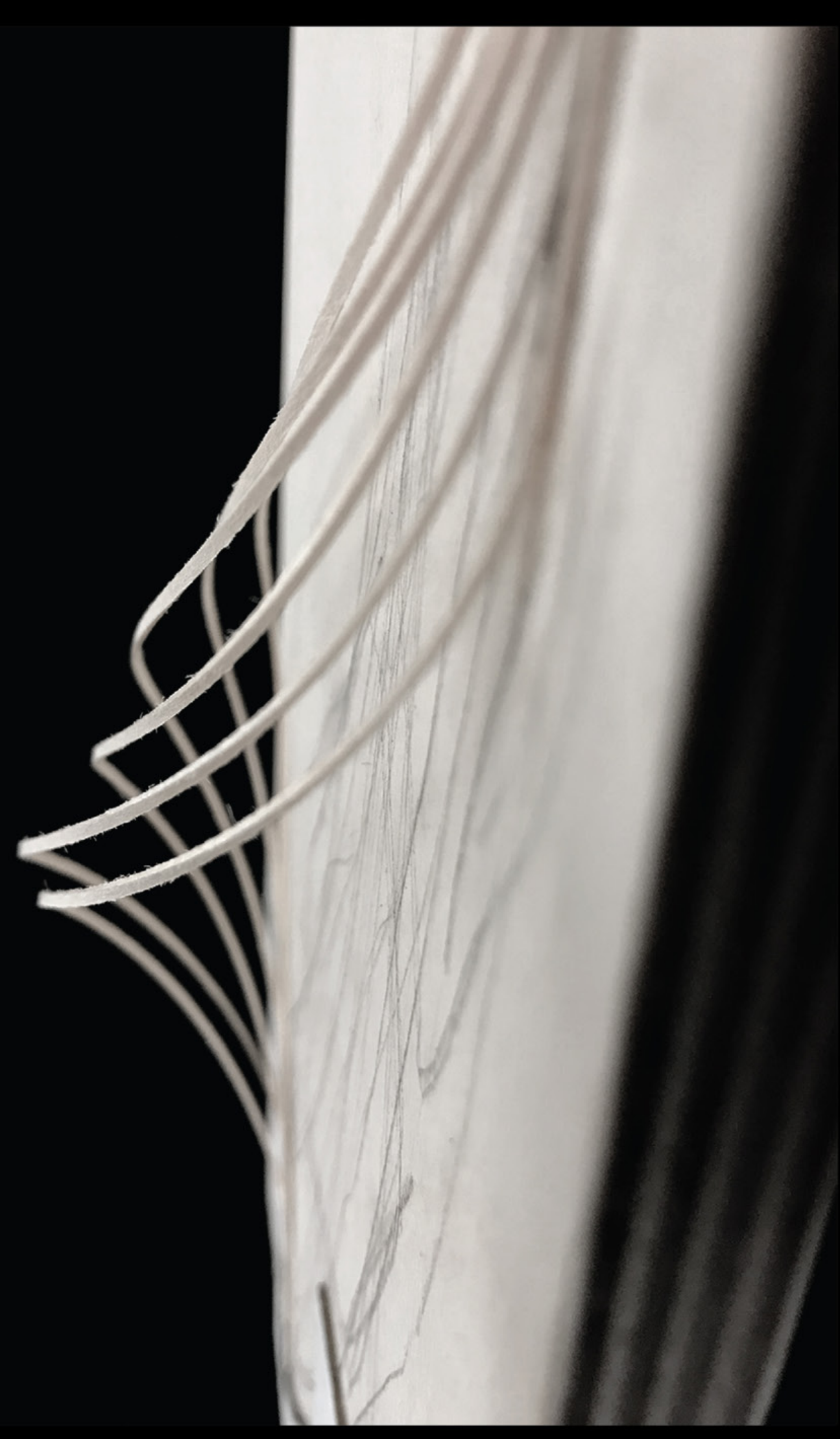

In pursuit of freedom in aesthetics, the disciplines of architecture and structural design have always worked hand in hand nexpanding new possibilites of form the modernisms approach and can be traced back to trajectories in structural cesign. The first is the gradua
reduction of mass, as exemplified in the Domino House and the Miesian language. The other is the transition from clear Euclidian geometries in spatial strucutres (such as the Pantheon) to a return of naturalism and free forms.

Optimization precedes superfluous forms. This project highlights the collaboration between architects and

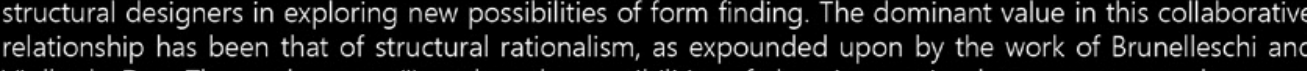
Viollet-le-Duc. The goals are to (I) explore the possibilitites of close integration between strucutral concept and architectural design, contrary to the conventional practice of a linear progress from archtiect's imagery
to structural engineer's implementation and to (il) discover the differences between geometry-based form making versus strucutrally-based rational form finding. Structure is not only a problem solving process but a key to new possibility in design 

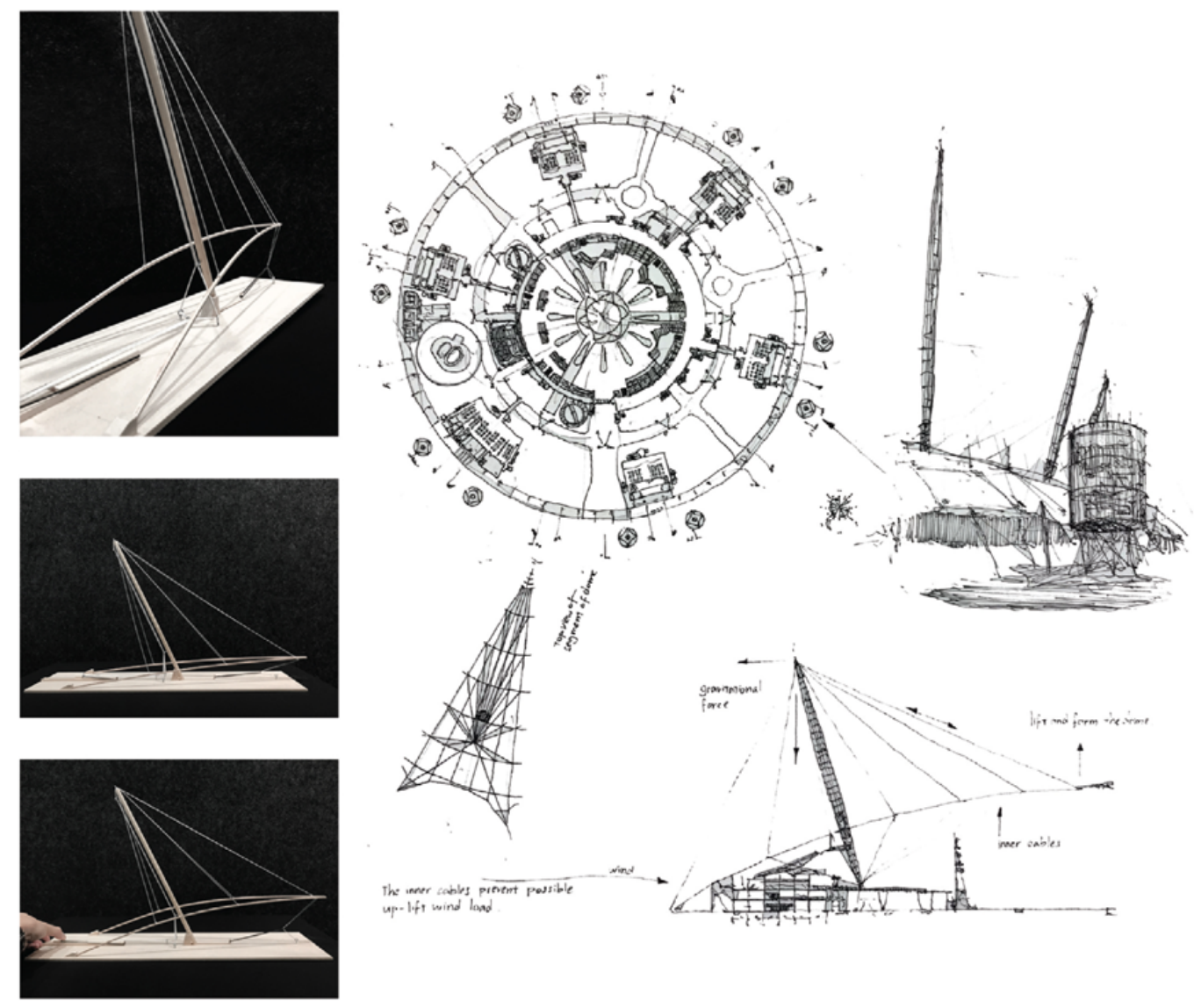

MILLENNIUM DOME

Part I - Research of major paradigms of form / structure with both historical

and more recent precedents. Four case studies were selected as the basis of

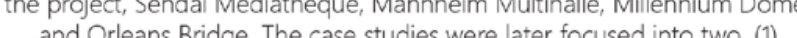

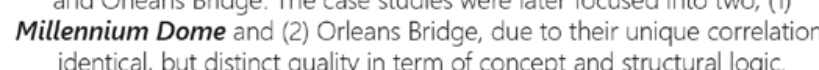

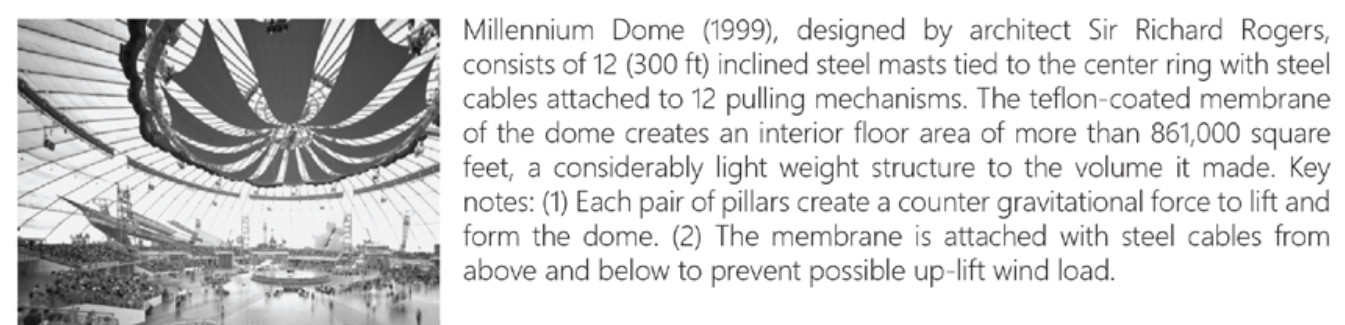

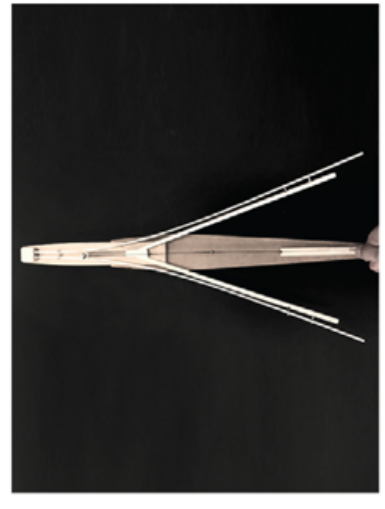

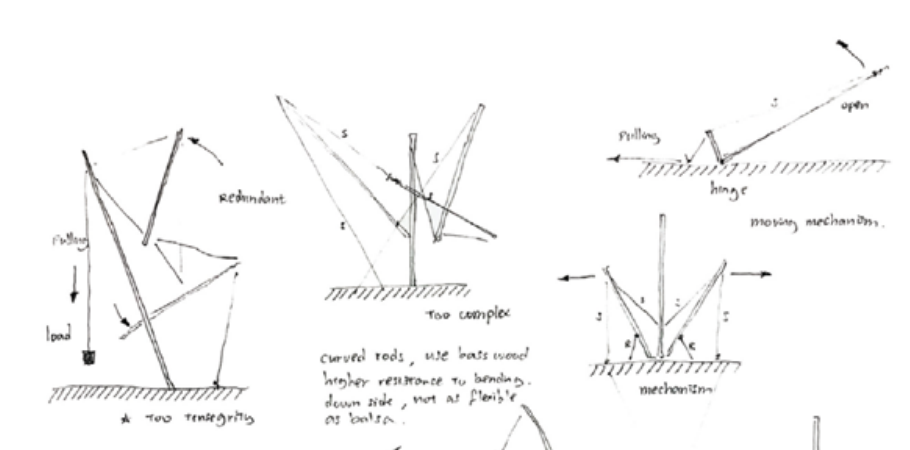
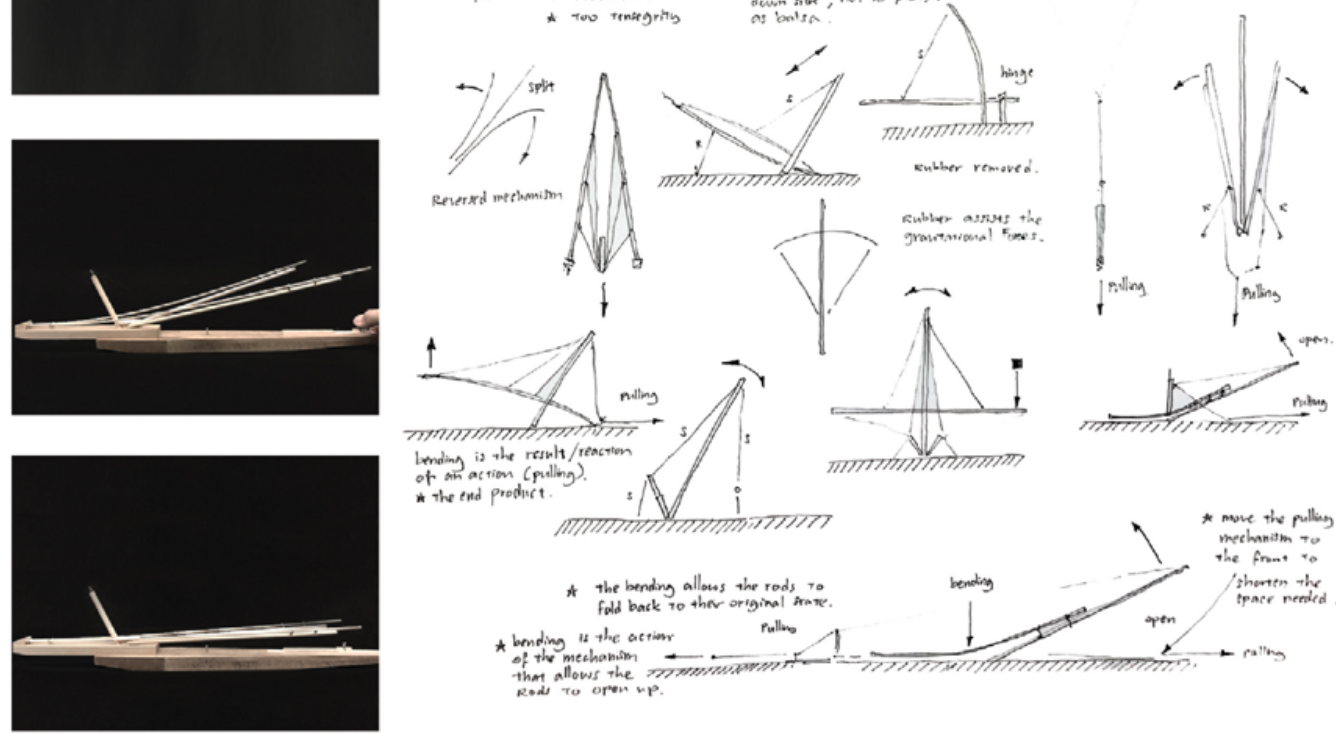

DECONSTRUCT / MILLENNIUM DOME

Part II - An experimental workshop, where a series of experiments through scale modelis to test the structural concepts were conducted In the case of movement in relation to form finding (kinetic). In contrast, the conducted maintain a respective form (static).

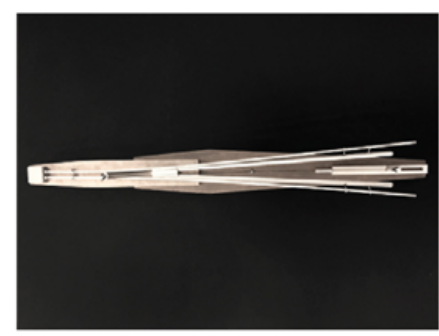

pired by the kinetic movement of Millennium Dome's study model, gured a new approach of an action-reaction mechanism. In the previous ods in varied tension levels on 3 different segments (bending woodien In this experimental model, the bending is causing a chain reaction which allows two rigid rods to span and return (bending = action). Through this , a reversed mechanism was discovered 

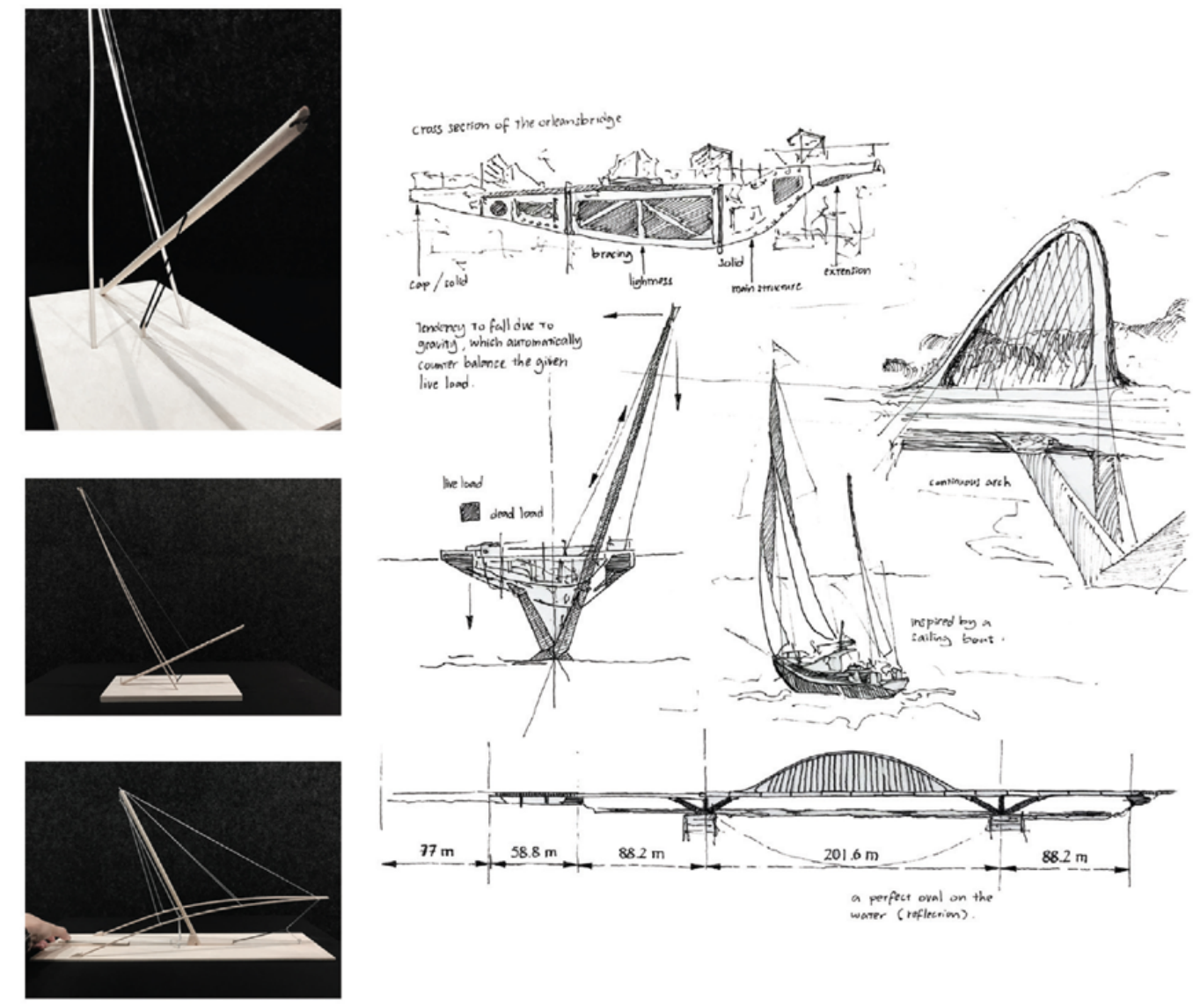

ORLEANS BRIDGE

Part I - Research of major paradigms of form / structure with both historical and
more recent proceder project, Sendai Mediatheque, Mannheim Multihalle, Millennium Dome, and Dome and (2) Orleans Bridge, due to their unique correlation, identical, bu aistinct quality in term of concept and structural logic

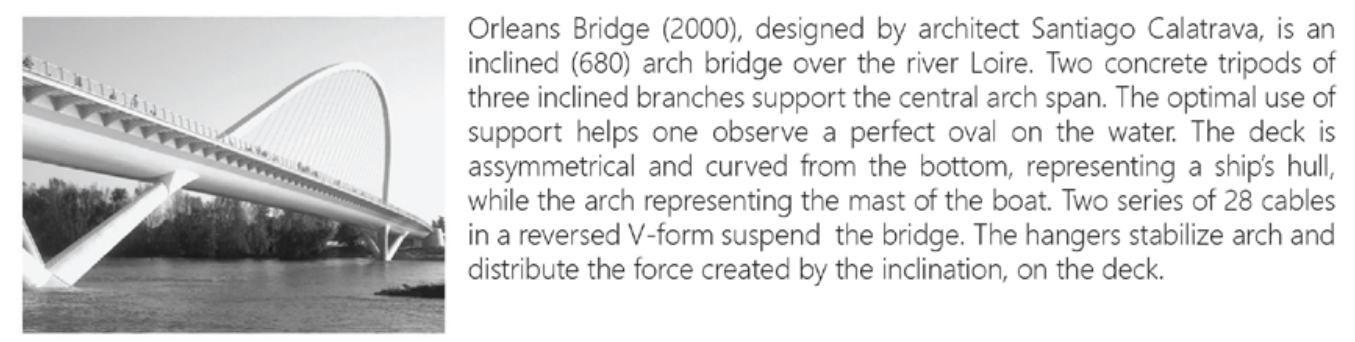

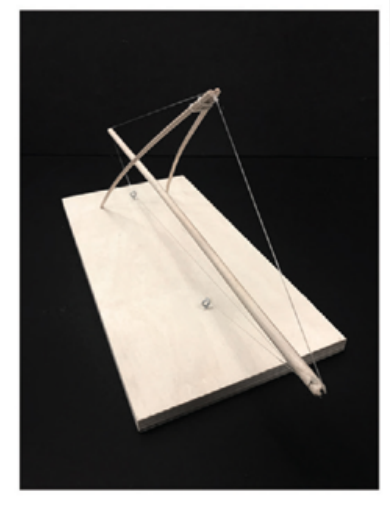
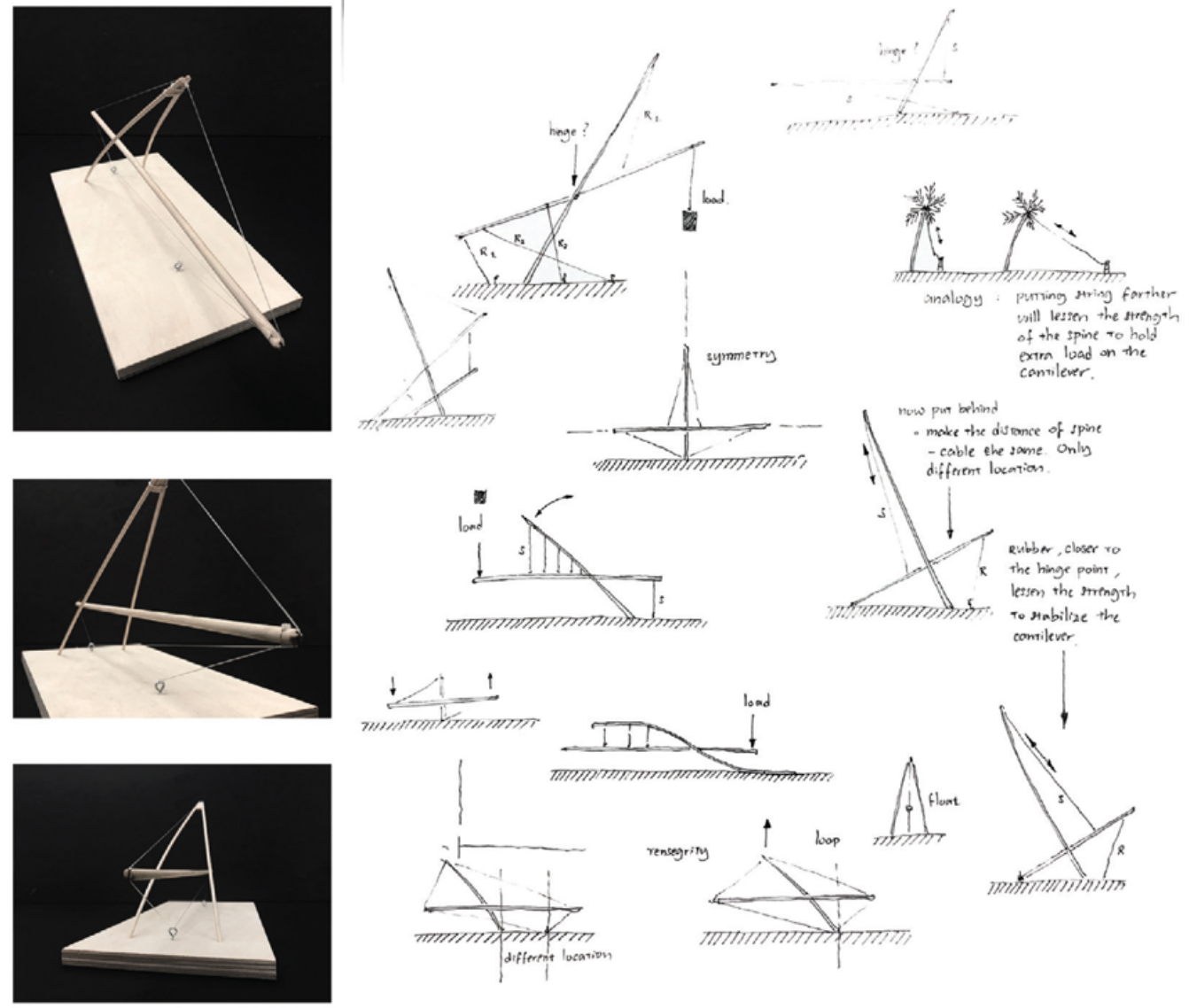

DECONSTRUCT / ORLEANS BRIDGE

Part II - An experimental workshop, where a series of experiments through scale models to test the structural concepts were conducted. In the casse of Miliennium Dome, lexperimented on the impact of mechanism and movement in relation
to form finding (kinetic). In contrast, the conducted experiment on orleans Bridge is about tension-compression relation to maintain a respective form

(static).

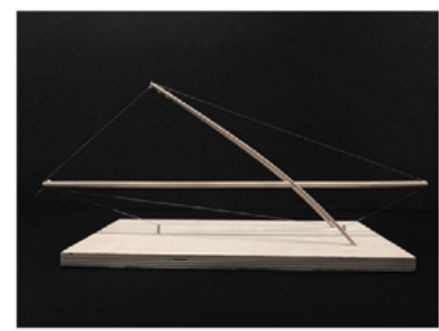
Derived from the Orleans Bridge's study model, this experimental mode
ms to use minimal contact to the ground while utilizing tension and (ompression to hold certain object, in this case a $6 / 32^{2}$ wooden rod. The wooden rod in place. The result is a simplistic structure of floating compression / tensegrity. 

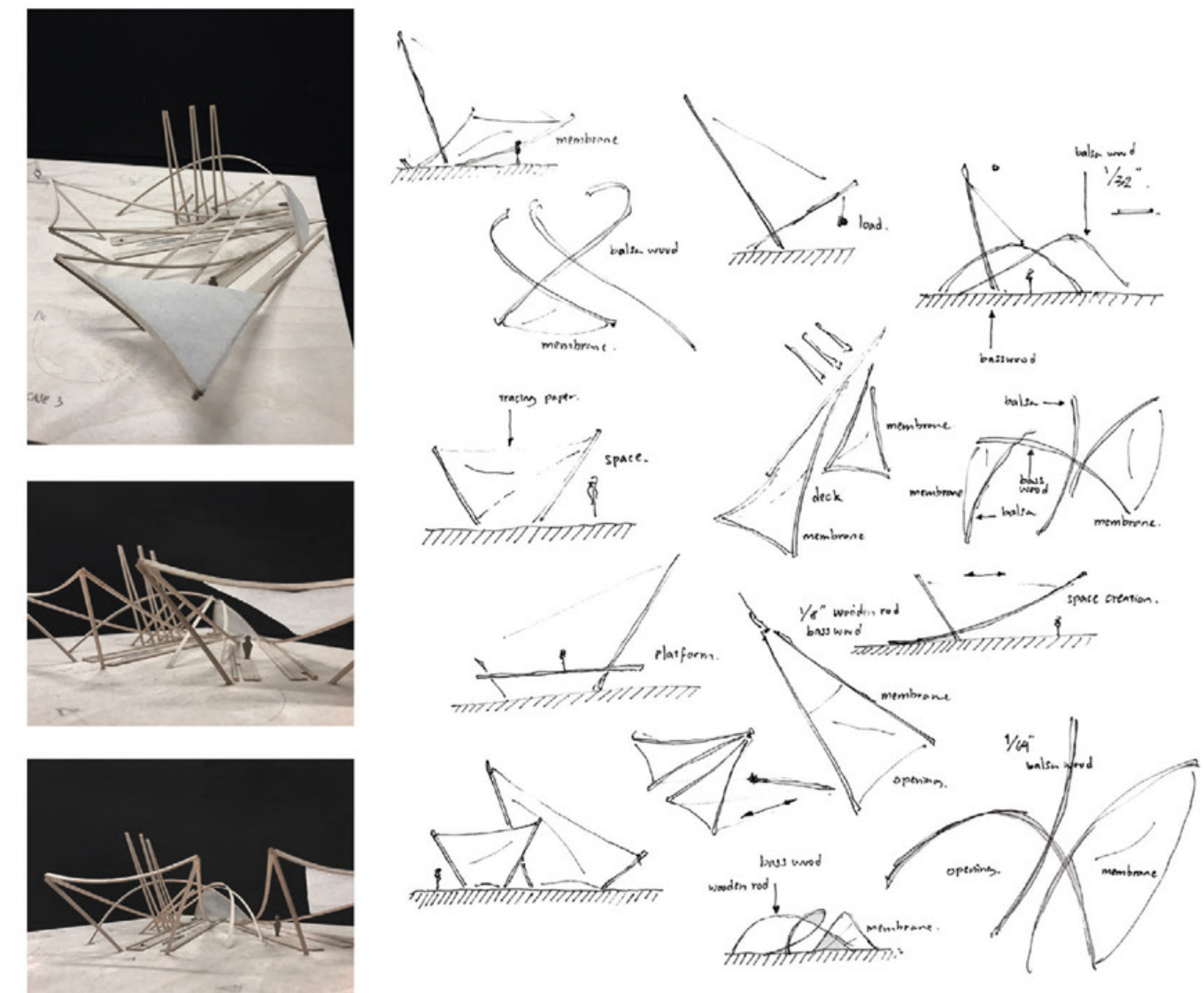

BENDING + SCALE

Part III - caps the studio with a design charrette that bases on the work between research information ond empiricical knowledge. Some more key factors were
added into consideration such as scale, proportion, and spaces into the into consideration such as scale, proportion, and spaces ins

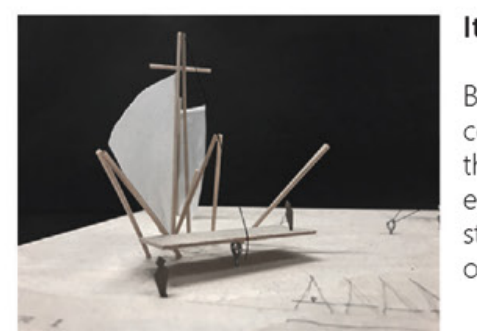

Iteration I

ased on previous study models, two new factors were added into

Bing (1) knowing the bending ligit of different wooden rods (2)

expermenting on breaking the symmetry of tension-compression structure, and (3) attempting a space creation through an amalgamation
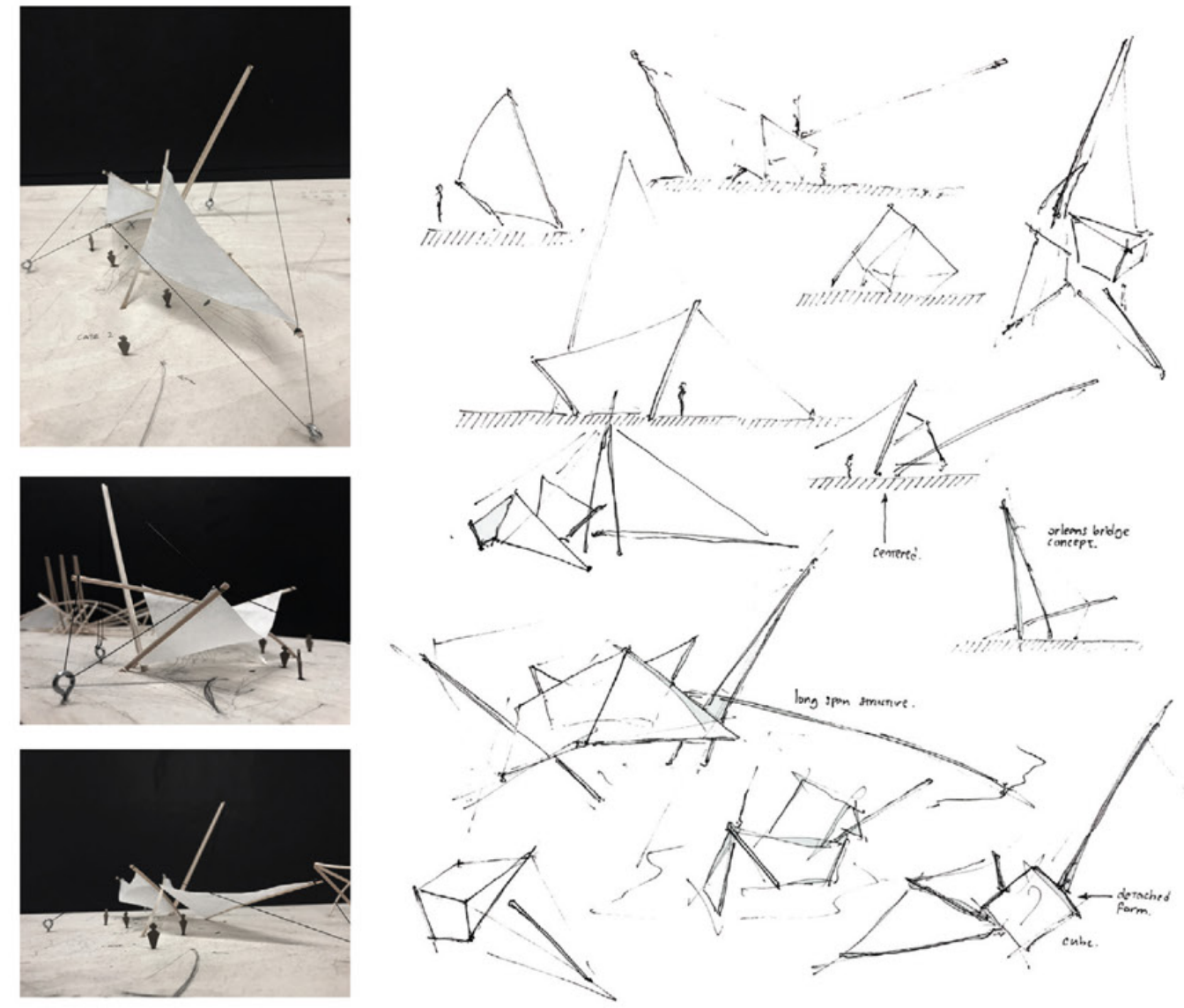

MEMBRANE + UNITY
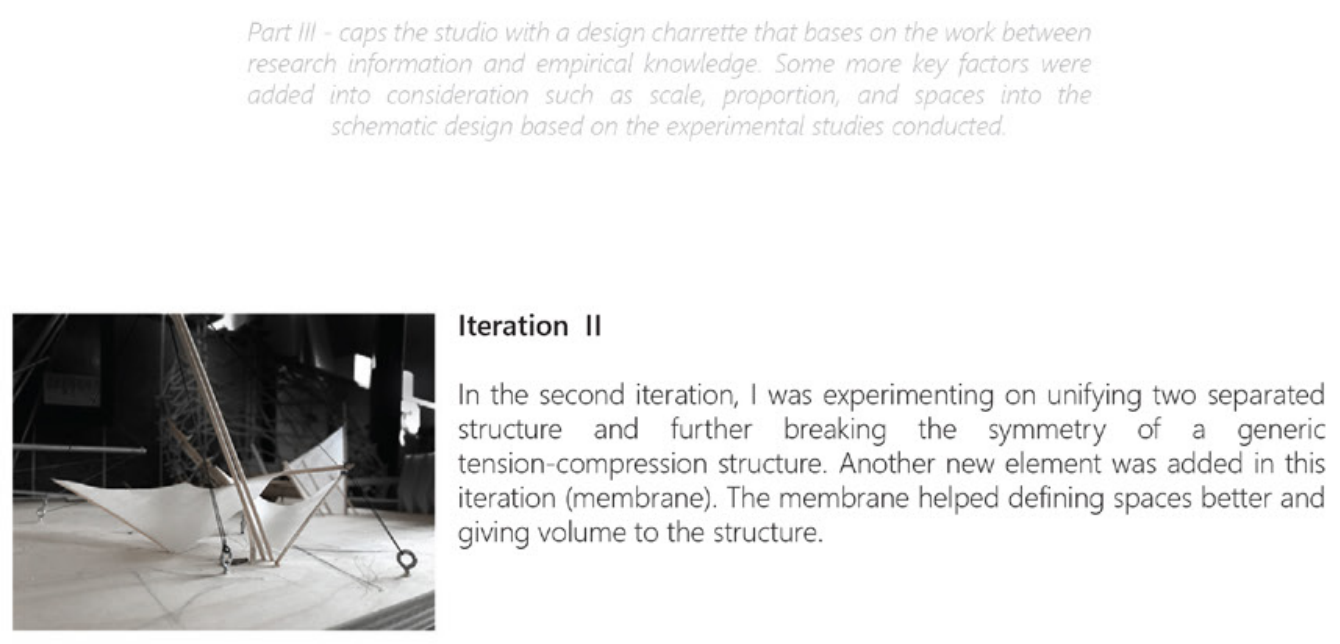

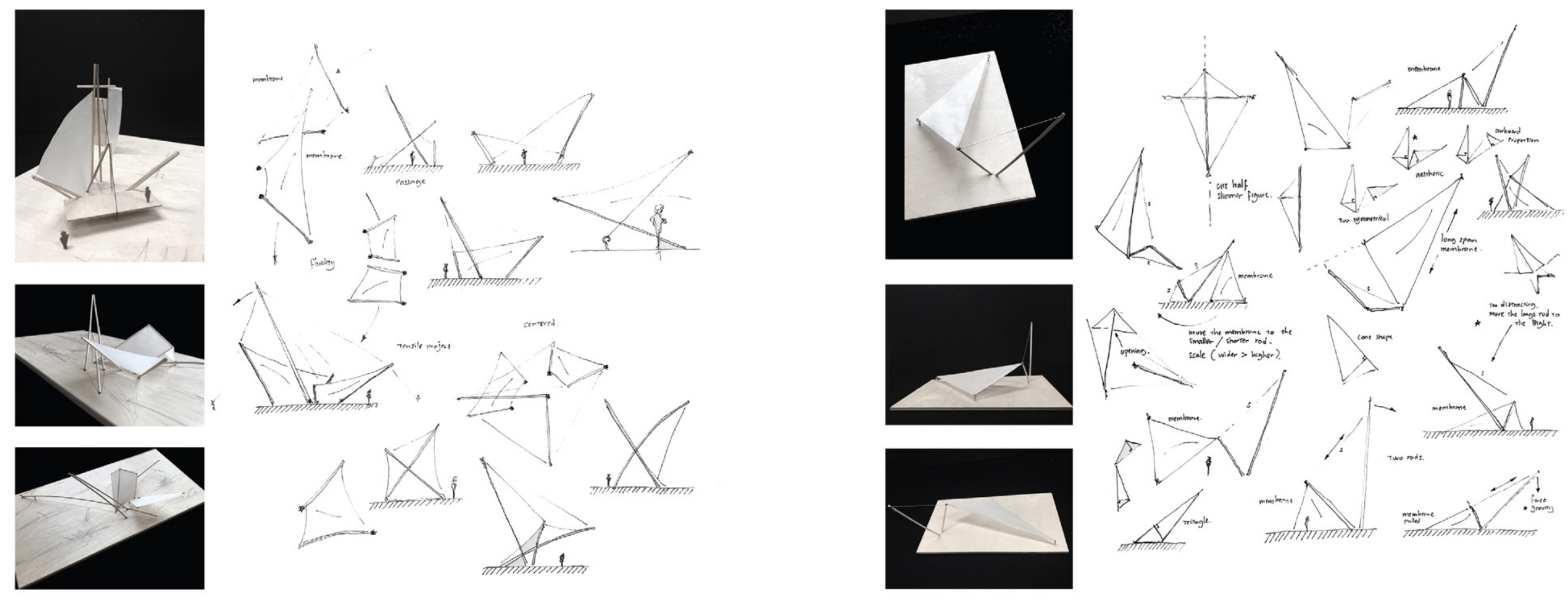

SCENARIO + DETACHMENT

LONG SPAN + EXTENSION

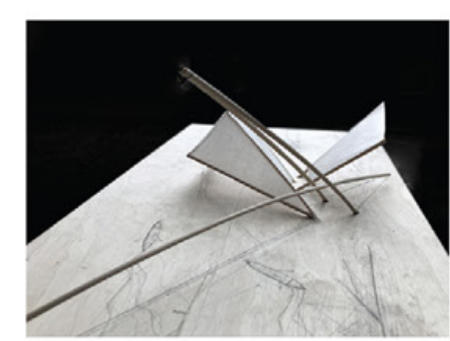

eration III

the third iteration, I was experimenting on giving the structure a ground to create a space, as it would be located near a lake. The spaces

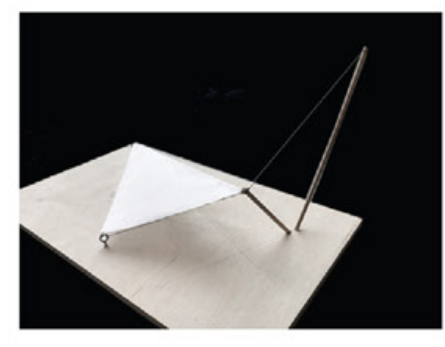

is iteration is a revision of a part of iteration III. I decided to remove the detached form and went along structure is only supported at comers ong span structure) and only using minimal components, giving a ghtweight appearance. 

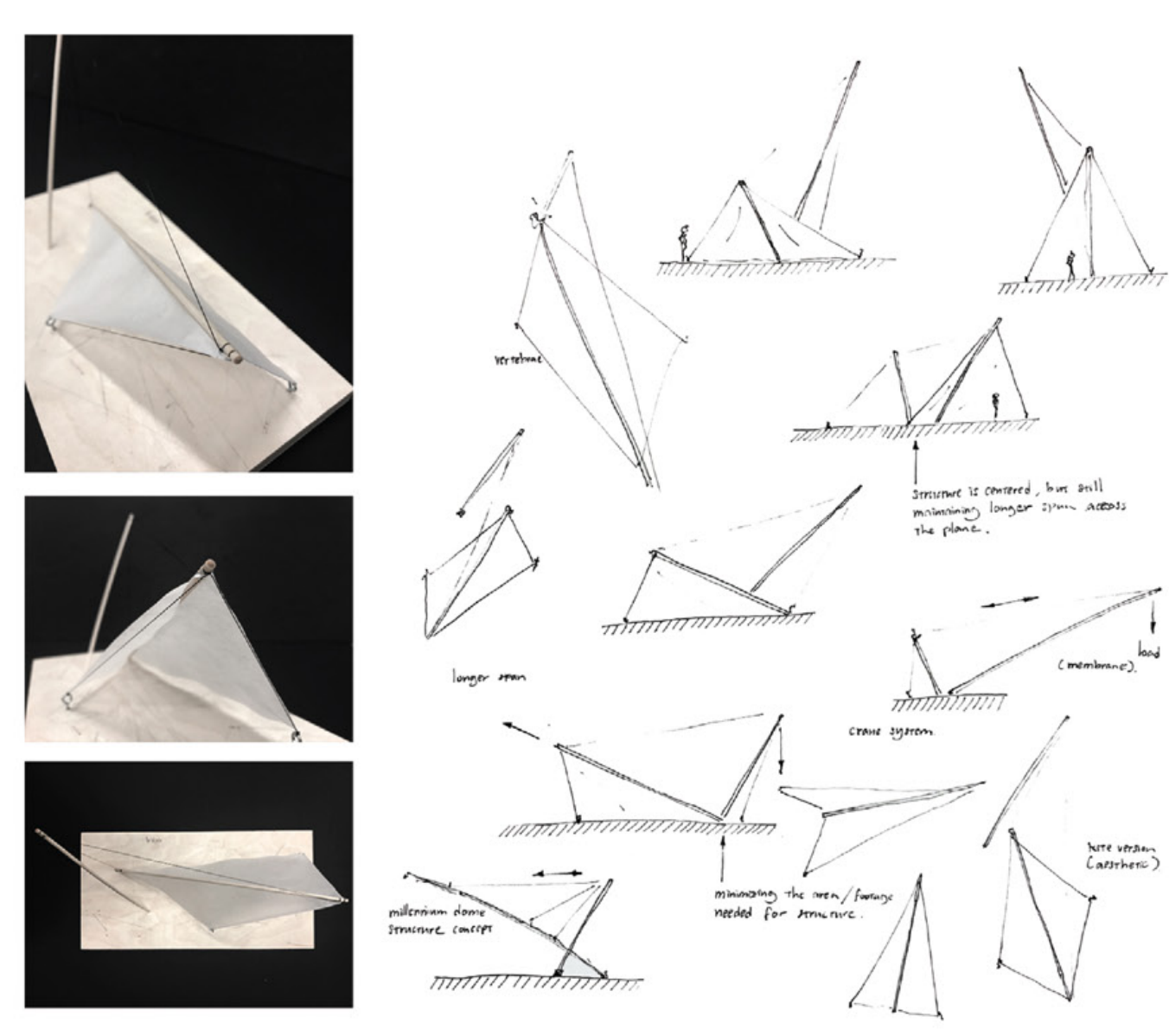

LONG SPAN + SPINE

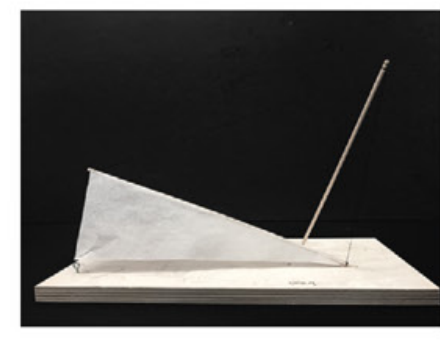

his iteration is a development of iteration IV. The use of two wooden rods to he vertical rod acts as a counter balance toward the leaning rod (esembling a vertebrae of the tent).
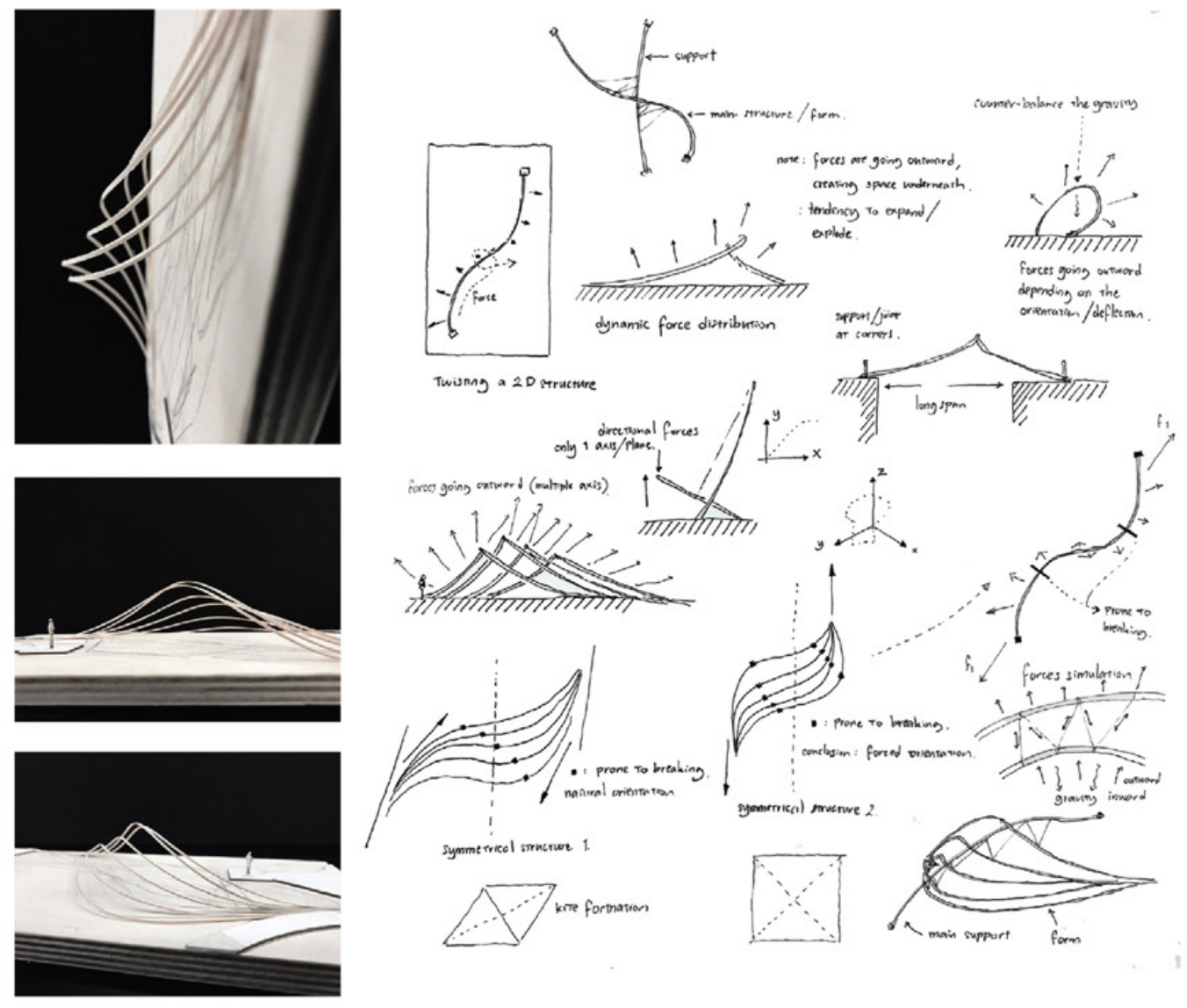

TWISTING + FREE STANDING

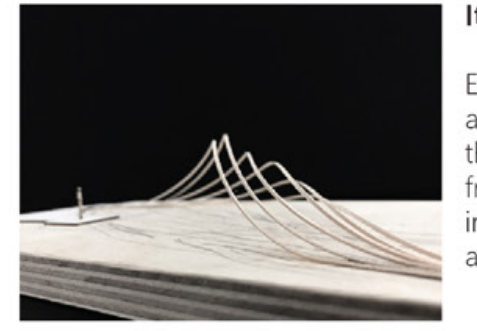

Eploration on tension-compression from $2 \mathrm{D}$ to $3 \mathrm{D}$. A new factor was ration (deflection) Through this ite hat a gesture as simple as twisting a wooden rod would create a
a -standing (tension-comoression) structure. This iteration would result a more dynamic design posibilities. Although free-standing, supports 


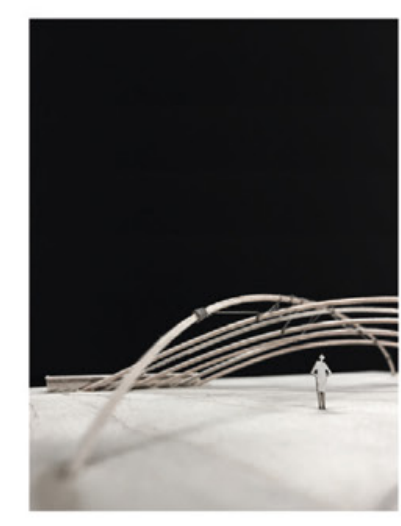

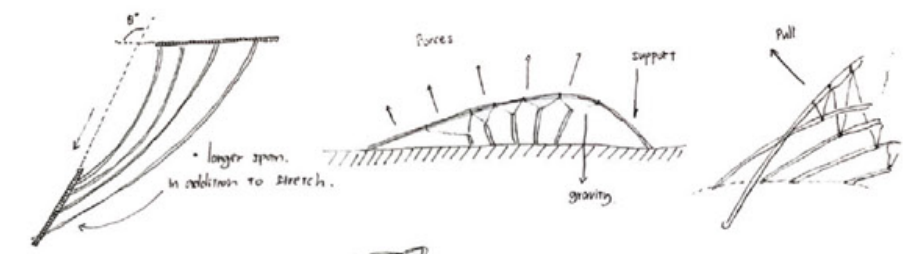

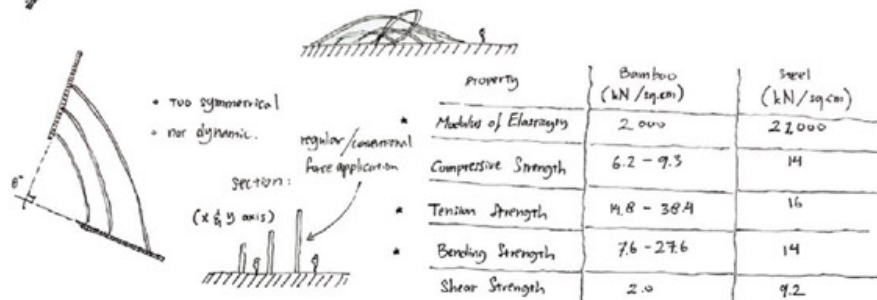

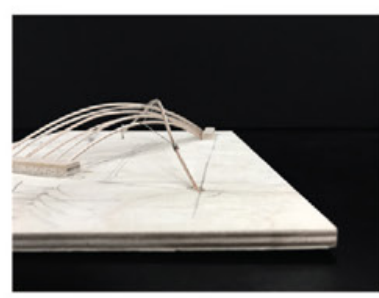

TIR

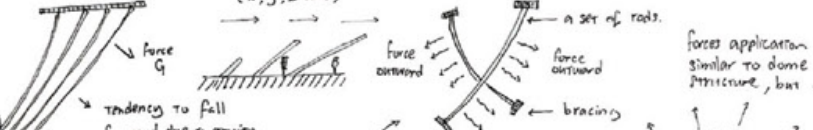
$P$ Then

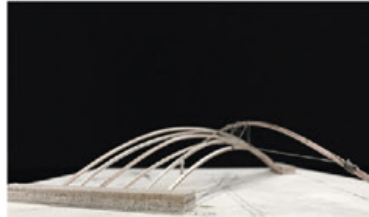

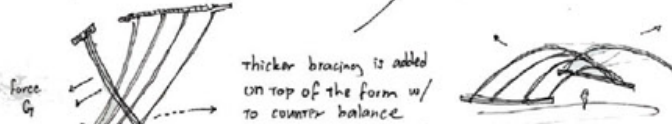

Sy.

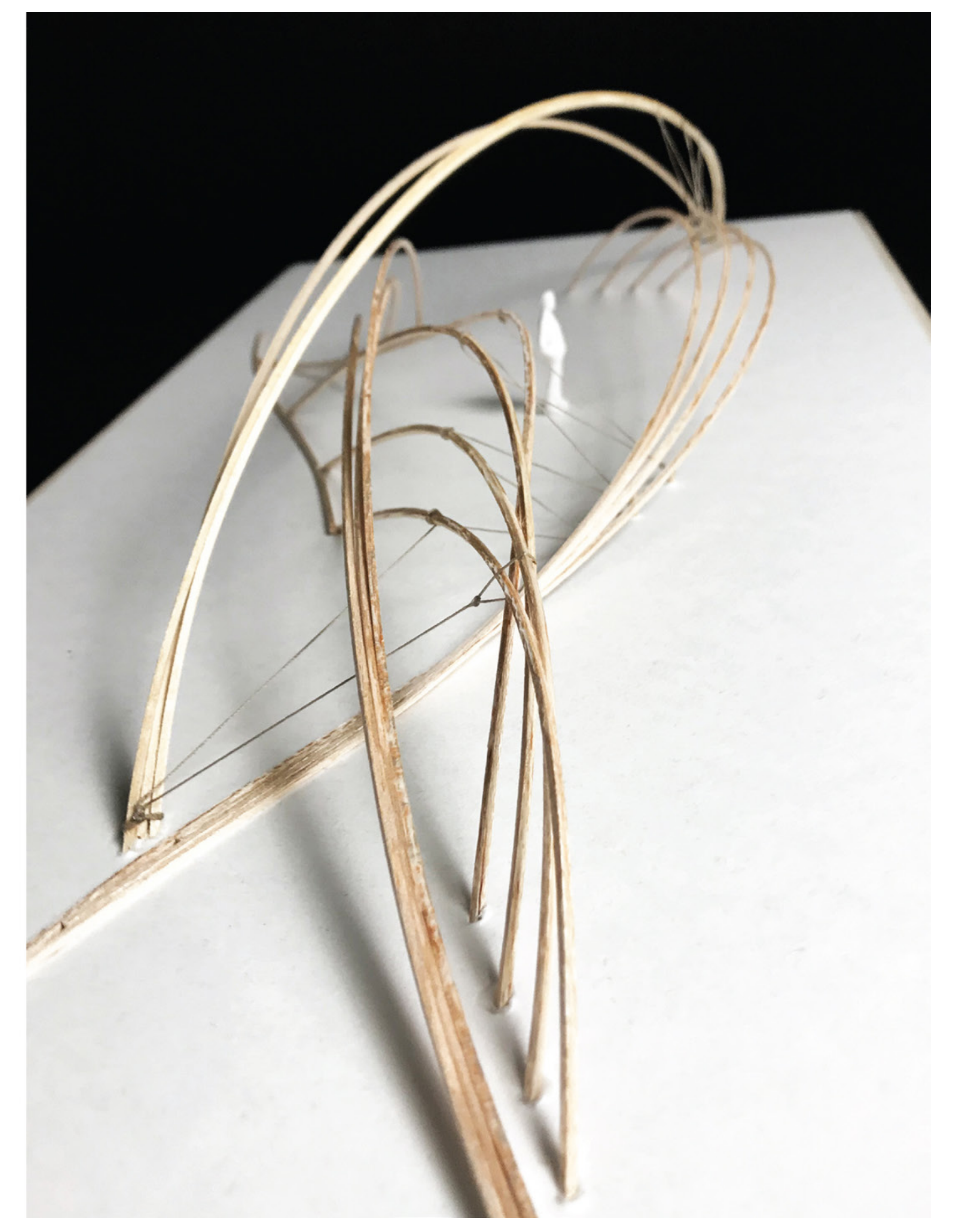

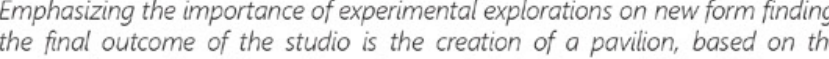

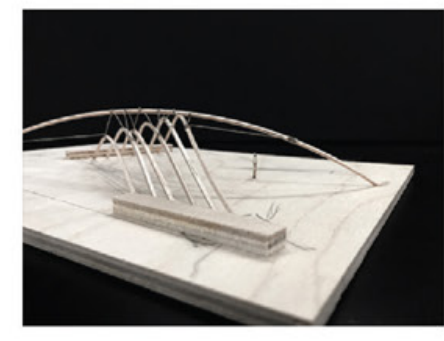

he pavilion. To create a space, a set of wooden rod

adjacent, but never parallel) on top of the set and fixed with strings. $A$

reat material option for the pavilion is Guadua Bamboo, due to its high

. 


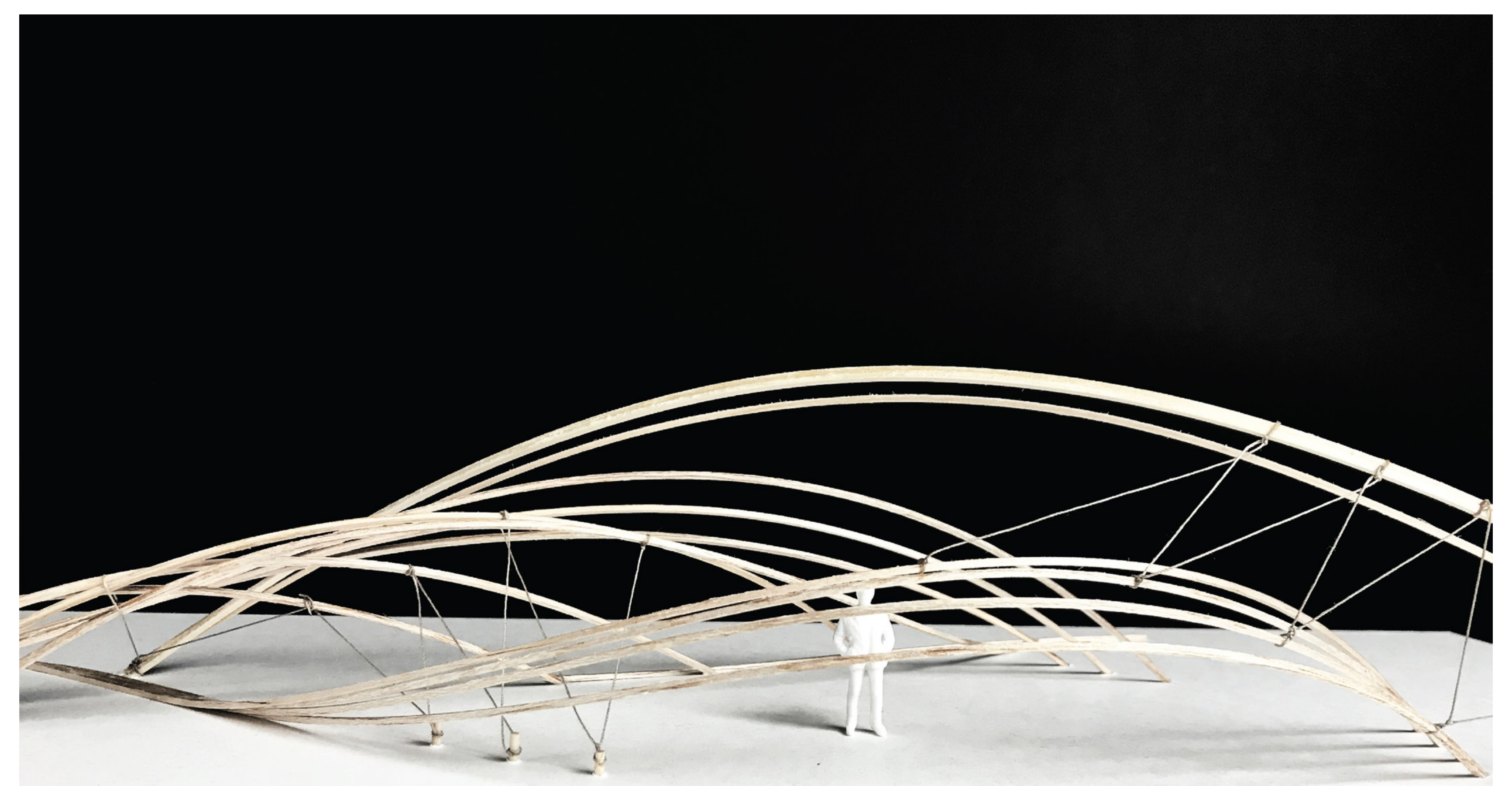


Work Type : First half, Group of two (In collaboration with Mitchie Qiao) (research)

Spring 2020

Second half, Individual (Project)
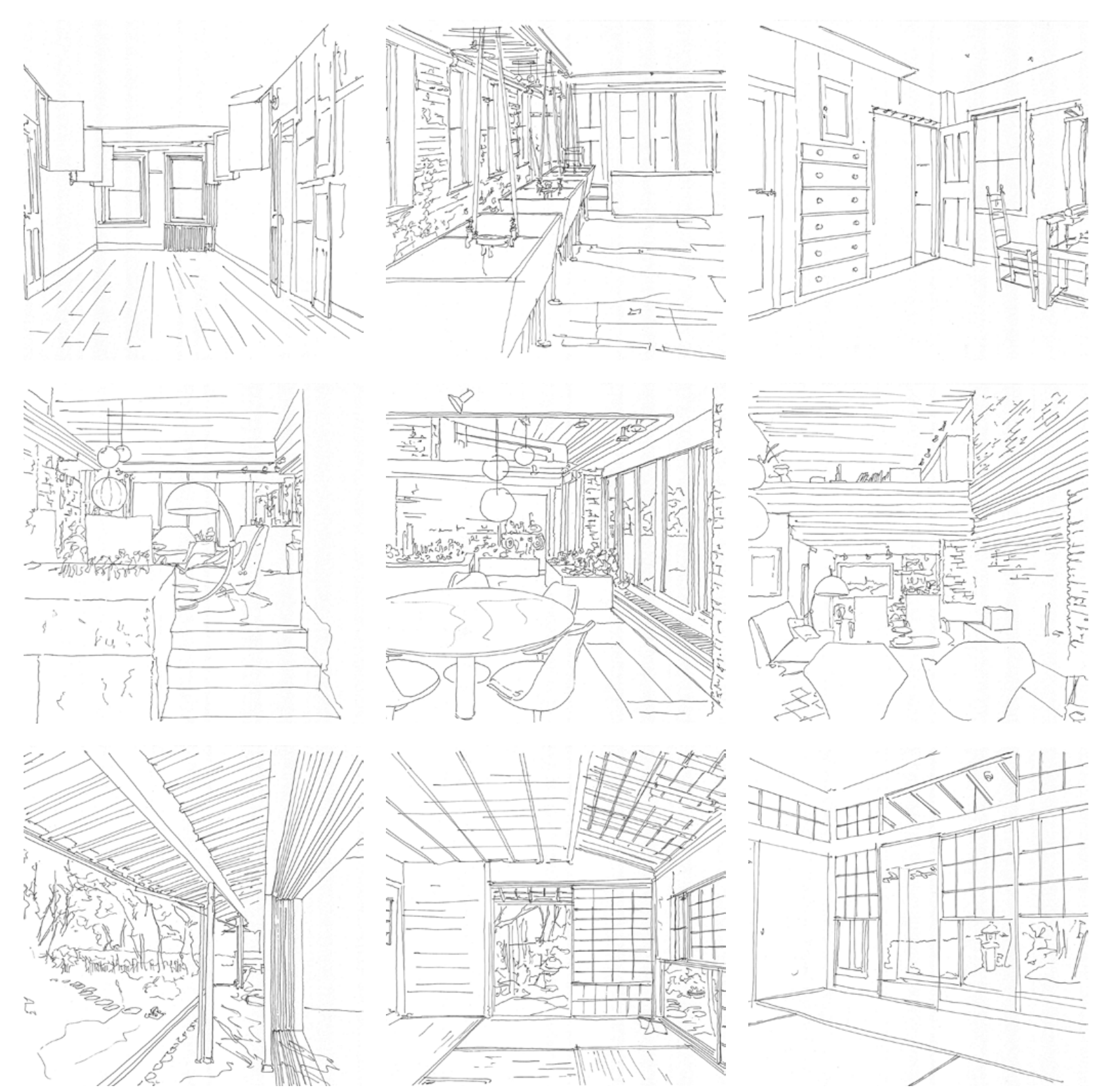

Case studies of different architectural projects

- The Shaker House

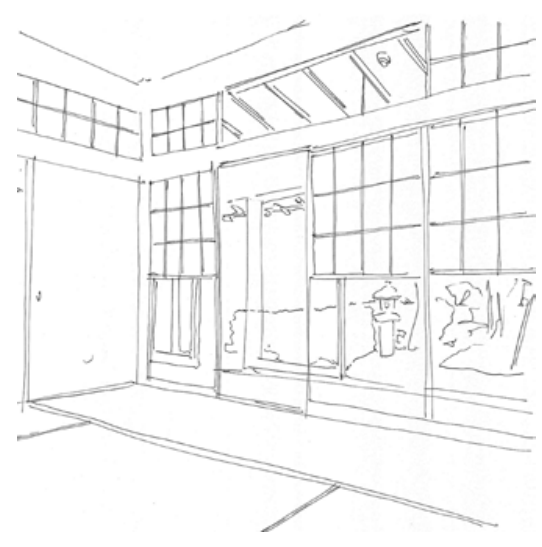

Van Driessche House

Micron pen

Inomata-tei
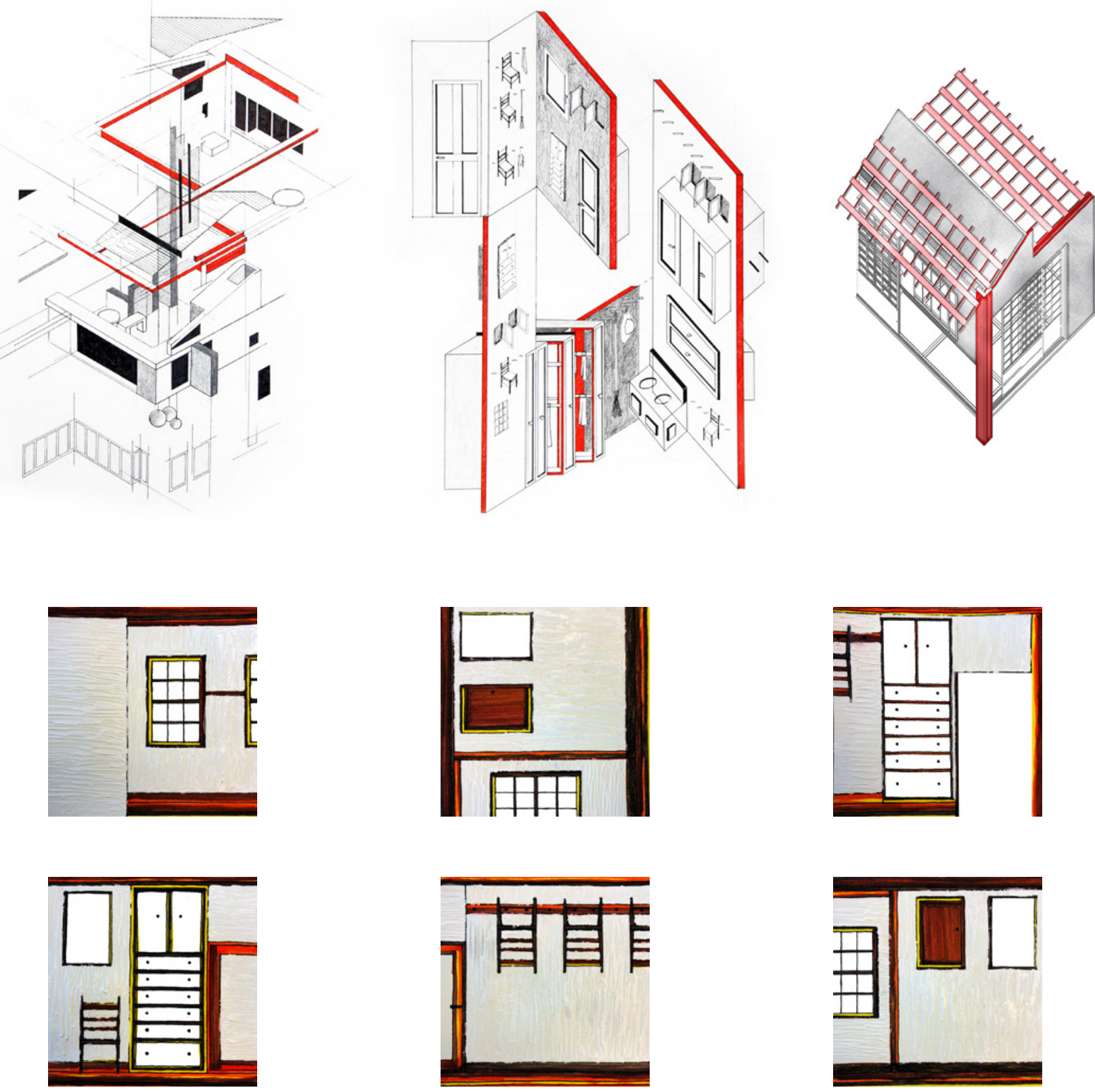

Case studies of different architectural projects

- The Shaker House

Van Driessche House

Inomata-tei 

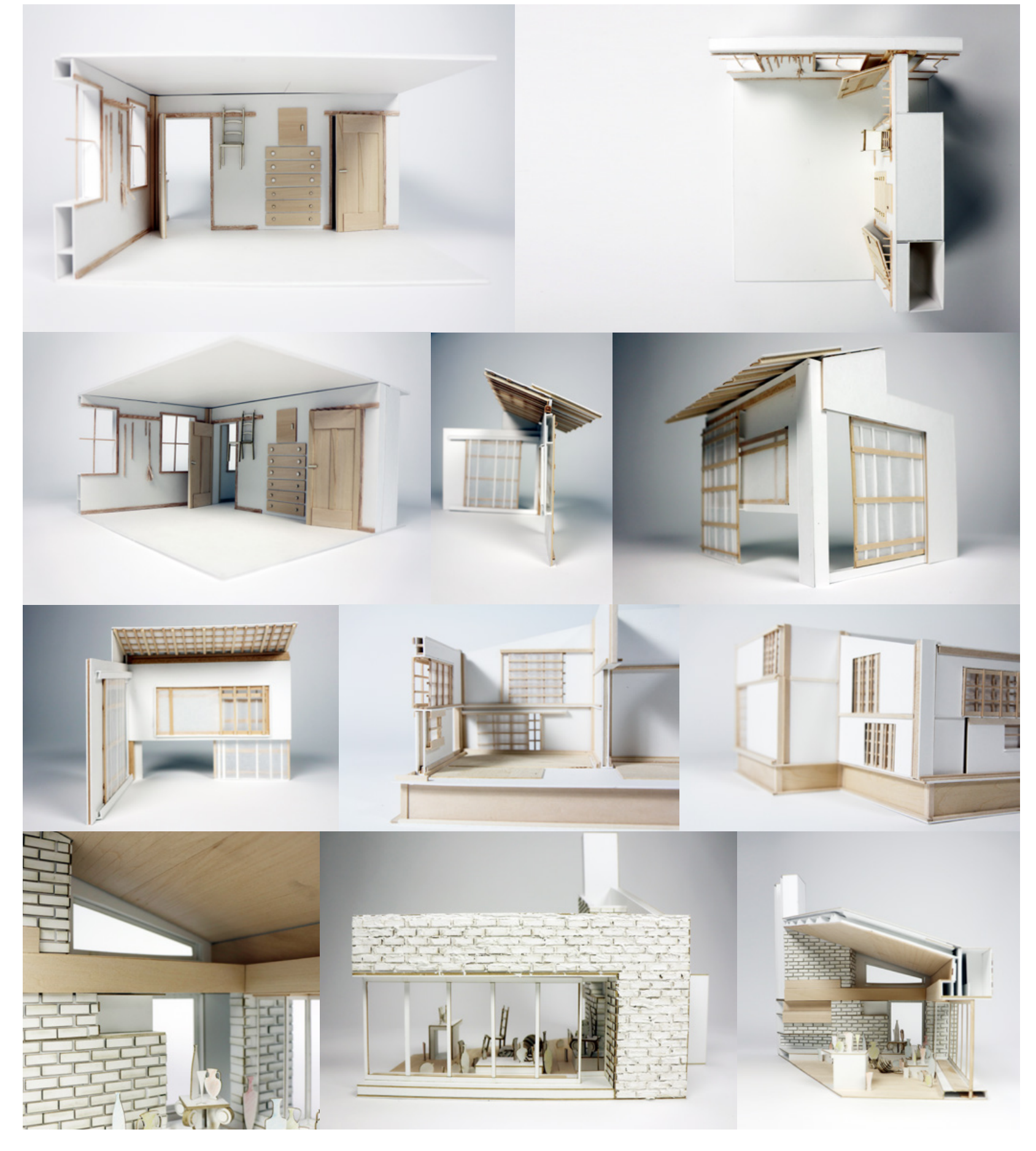

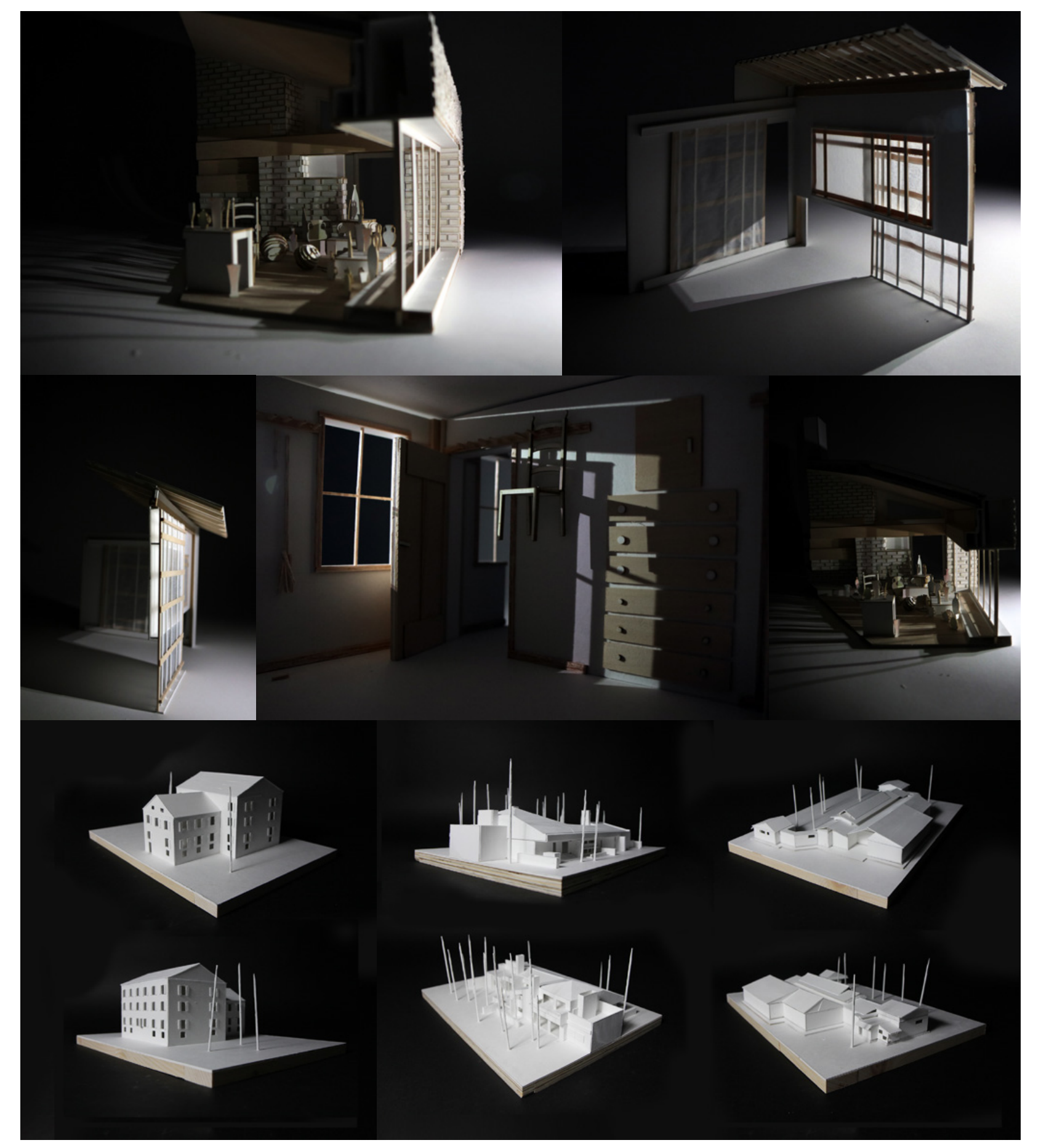

Case studies of different architectural projects

- The Shaker House

Van Driessche House

- Inomata-tei 
As I ascend up the stair, toward the small aperture at the corner, I can already hear distant volces of exctement, he sound of wind and rusting leaves, bids chiping, por face and diminishes into the horizon

"I always dreamed of having a window with view. The window asks for a view don't yo hink? A view of zen, a serene landscape

complete with oasis of plants, flowers,

and trees. Who wouldn't dream of such
panorama in the midst of this chaotic world"

Here is a place I called hom

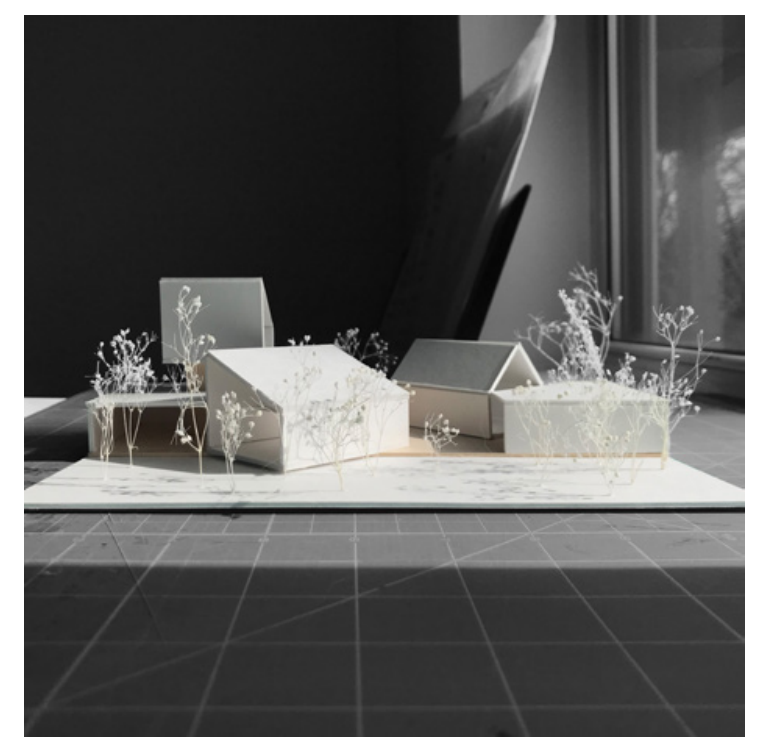

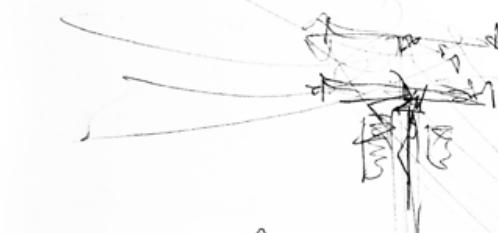
Setagaya City Tokyo 157-0066
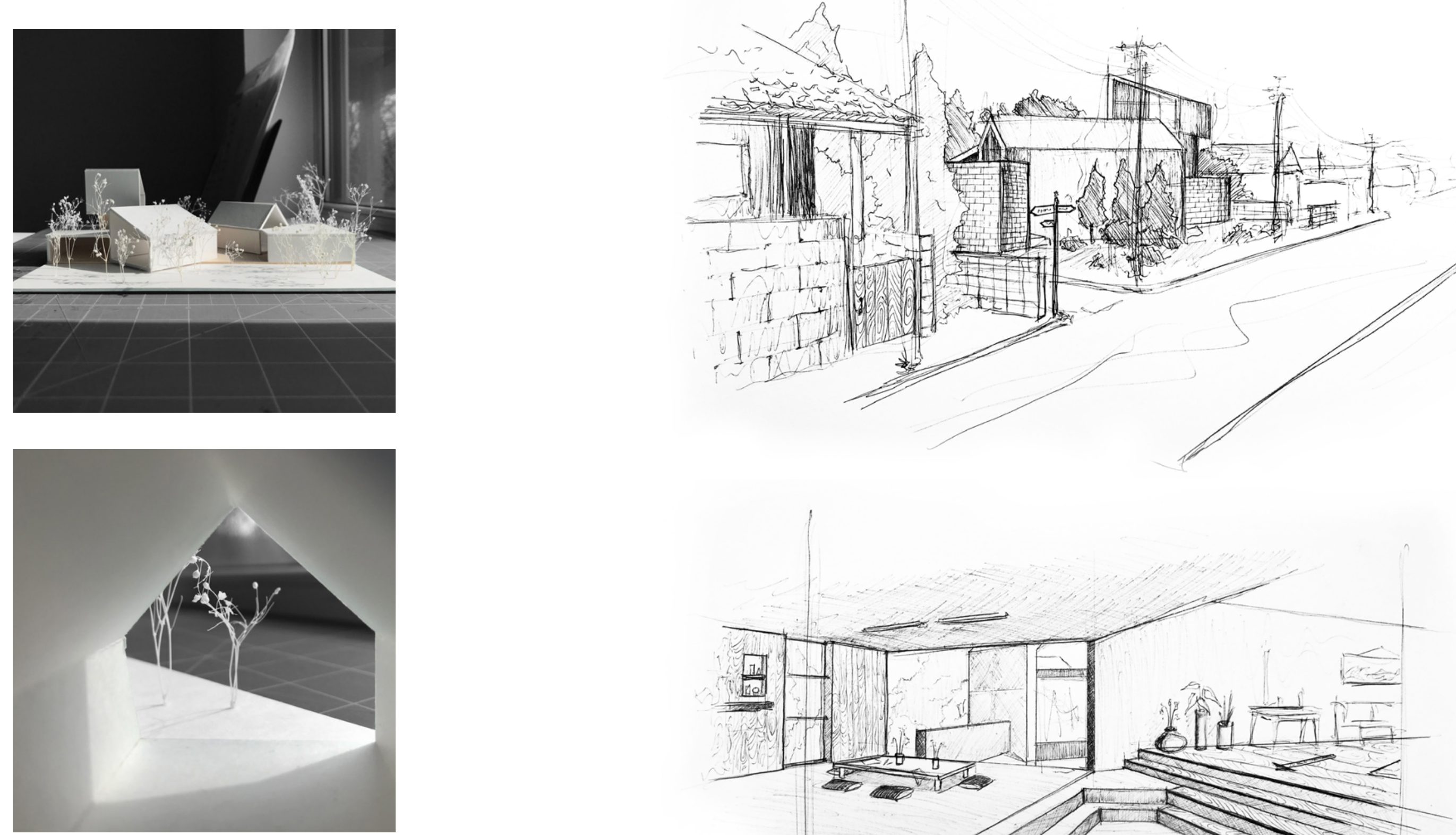

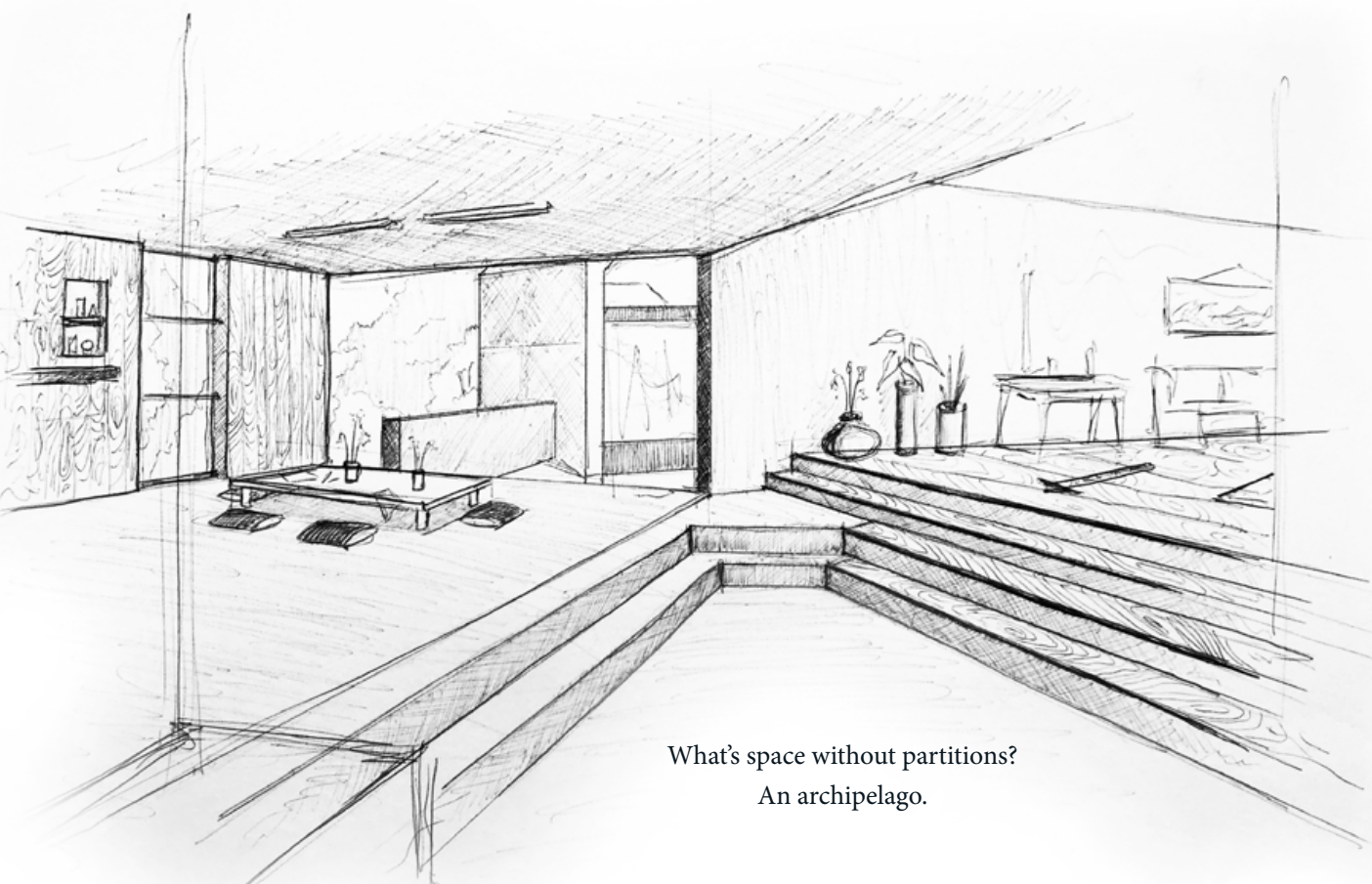



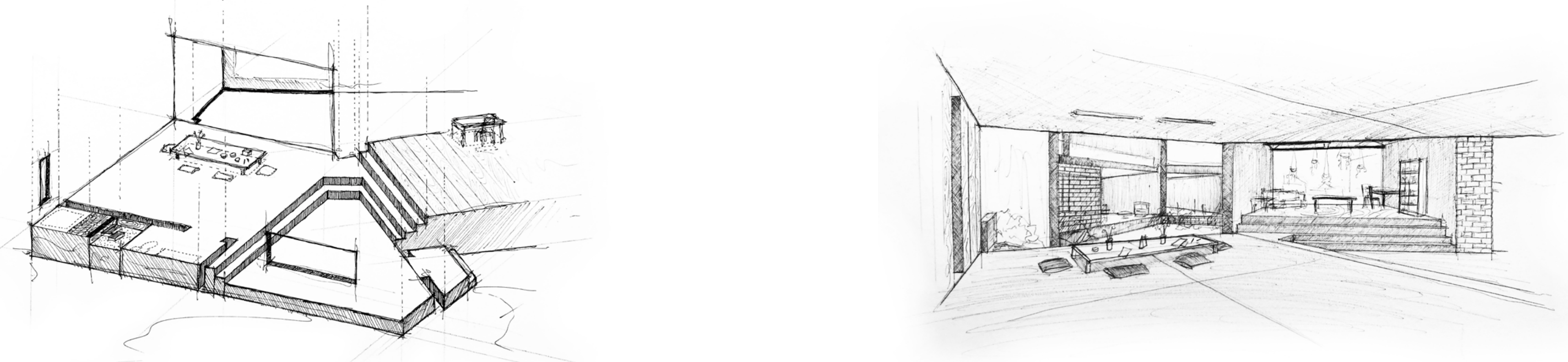
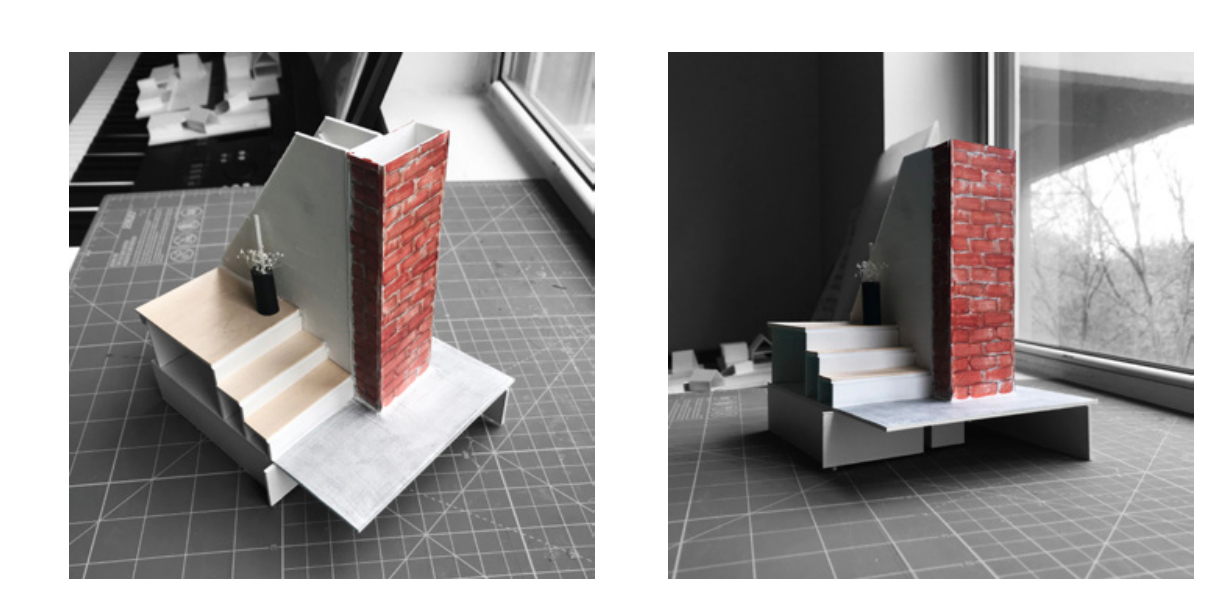

$$
\begin{aligned}
& \text { There is magic in its fragrance } \\
& \begin{array}{l}
\text { There is solace in its taste } \\
\text { And the laden moments vanish }
\end{array} \\
& \text { Somehow into space }
\end{aligned}
$$

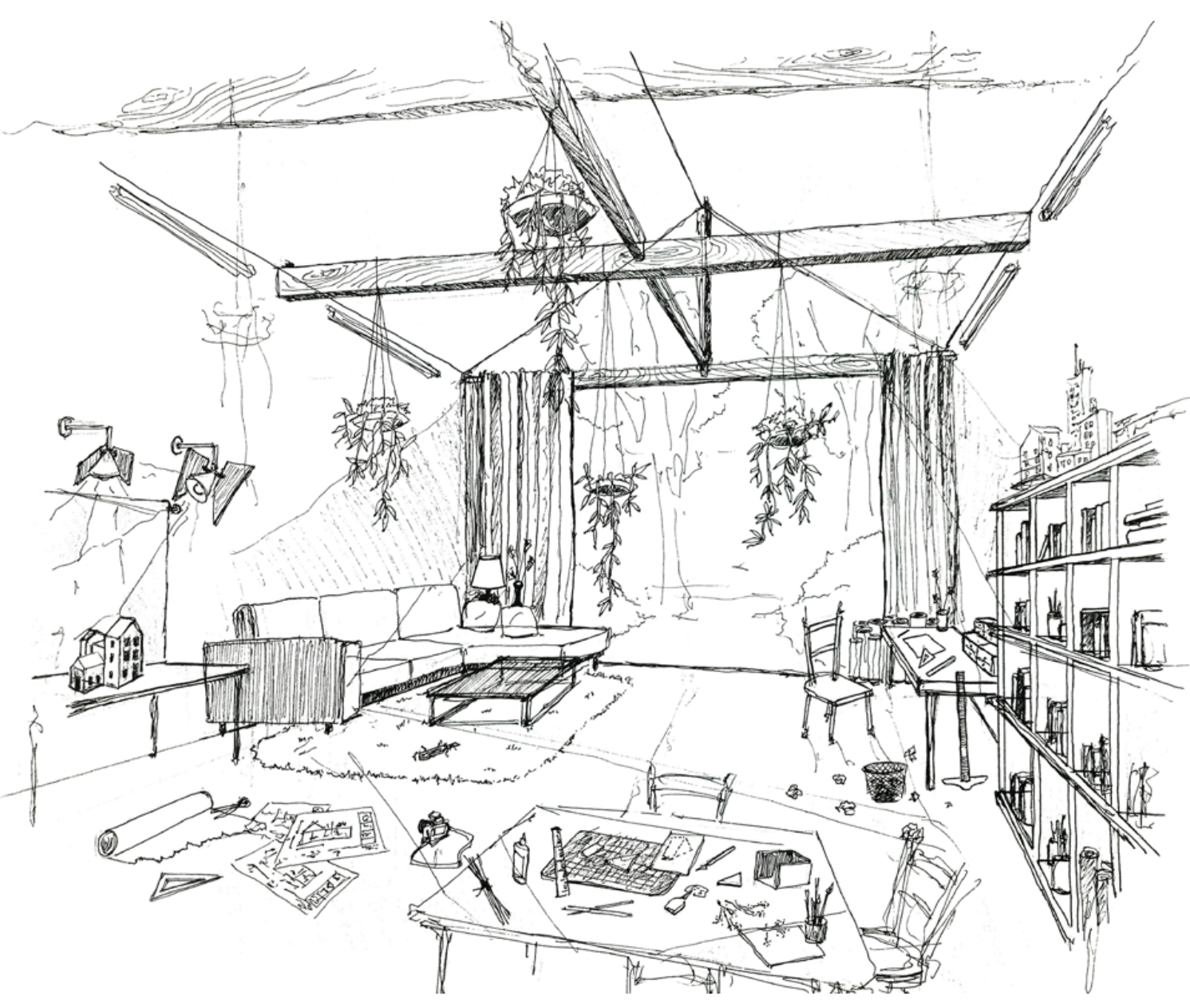



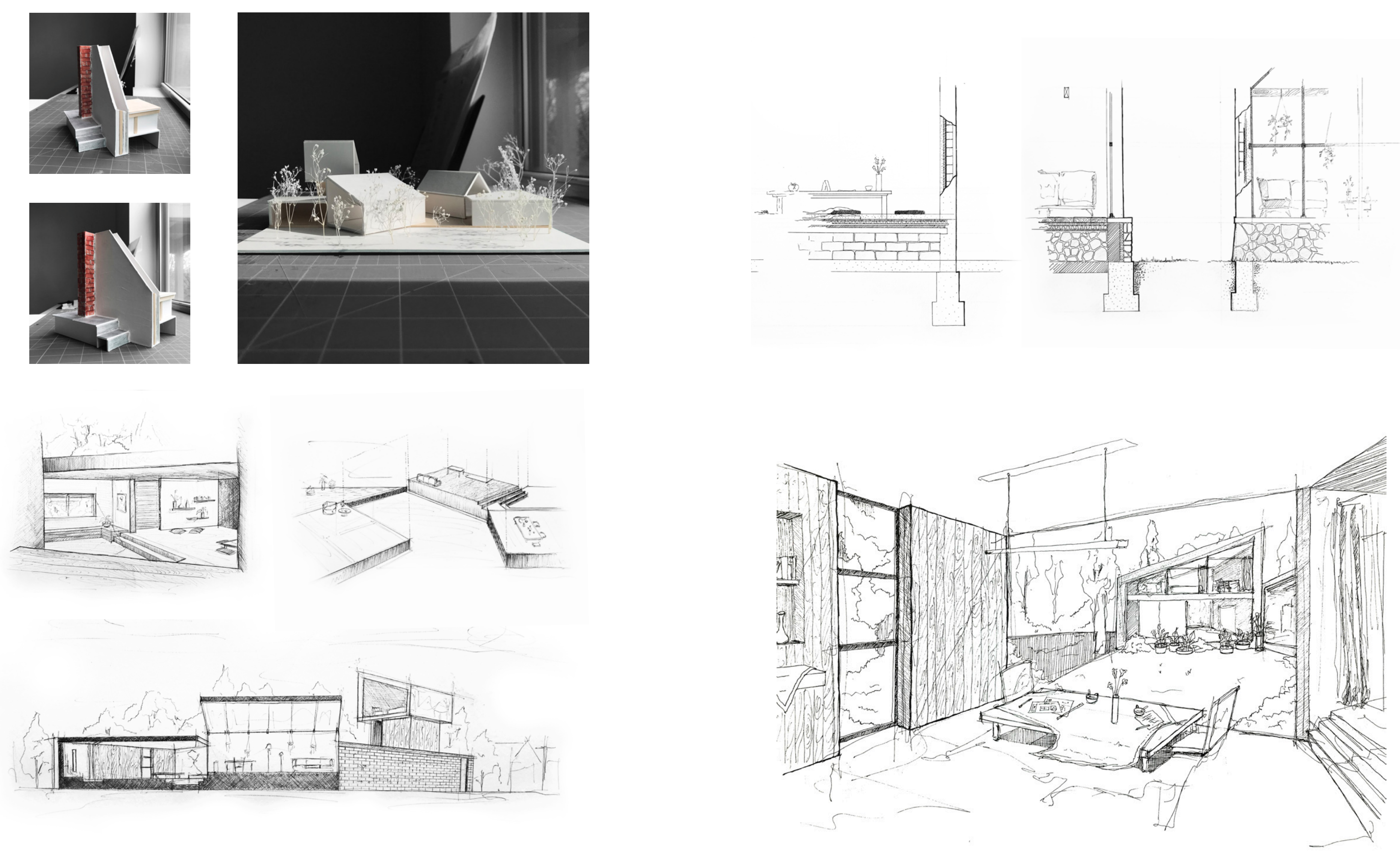

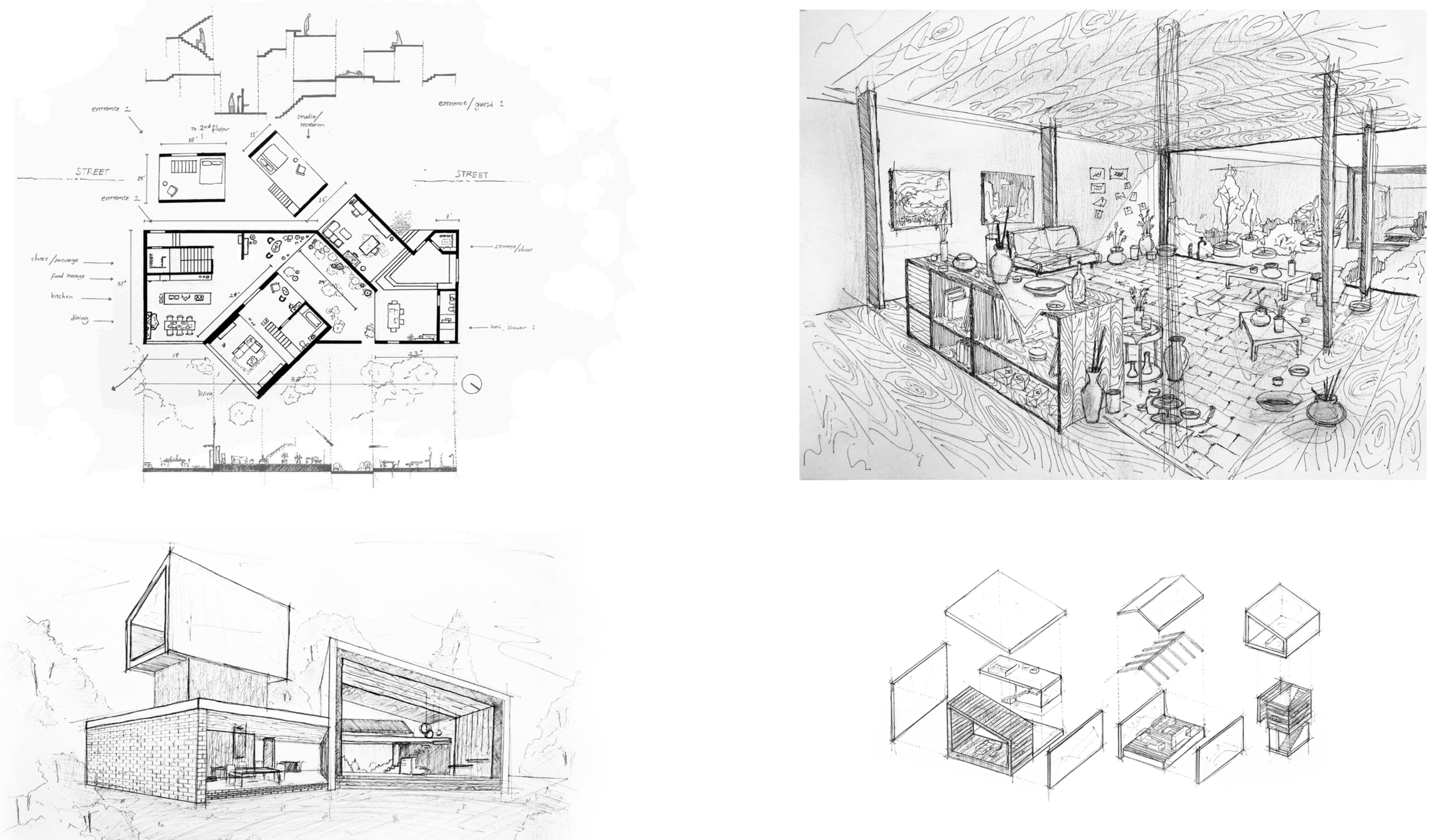

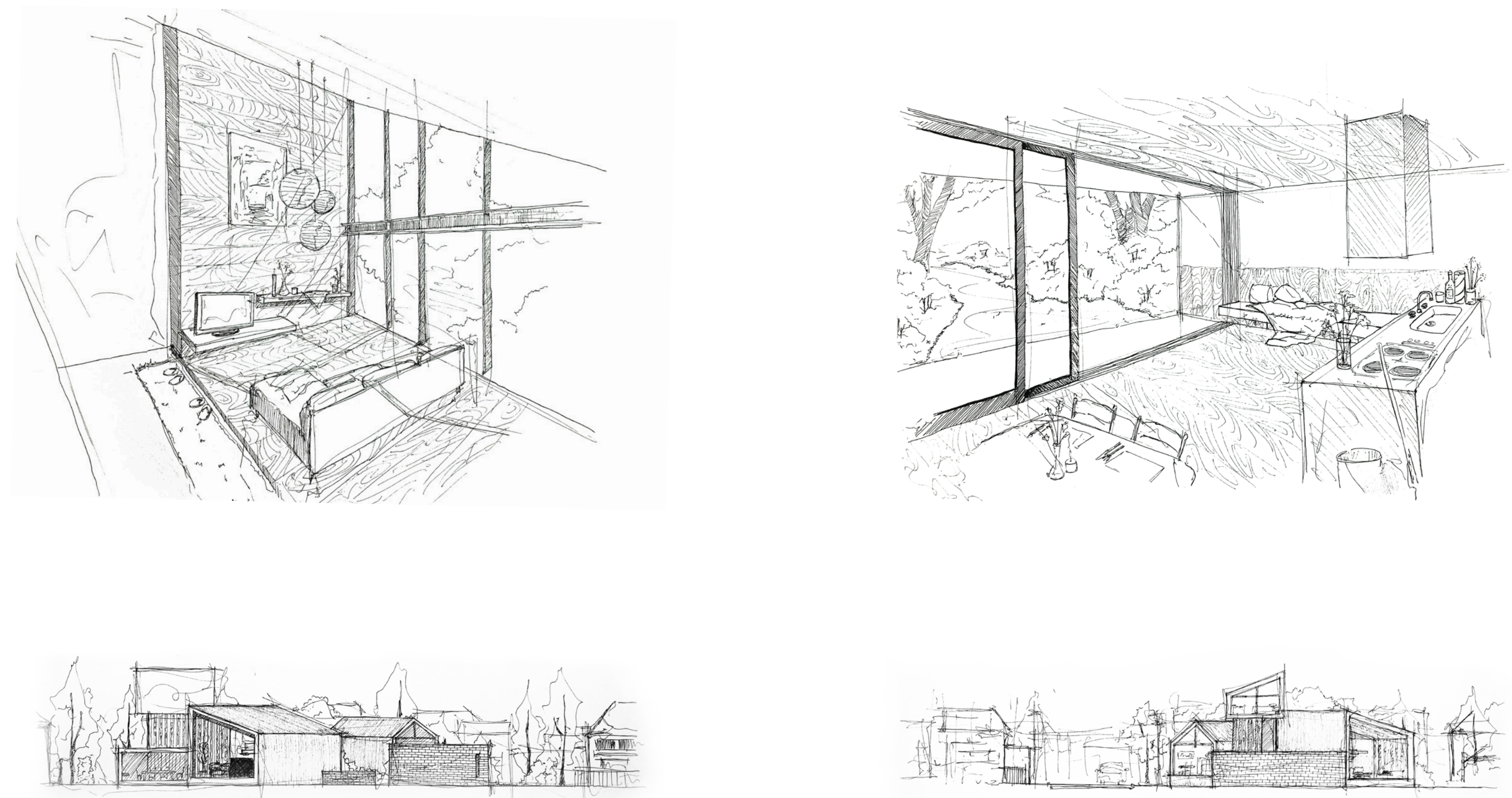

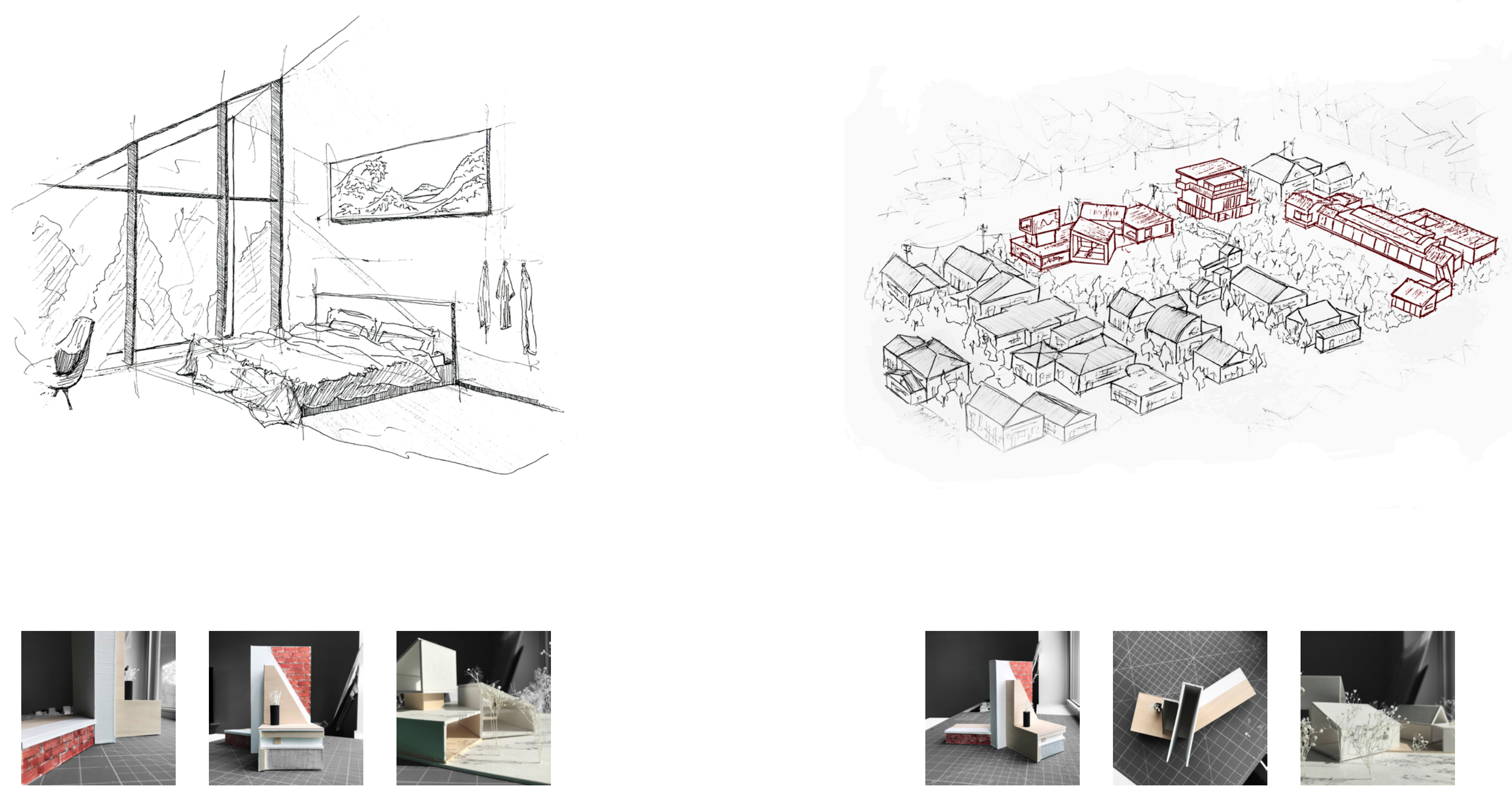


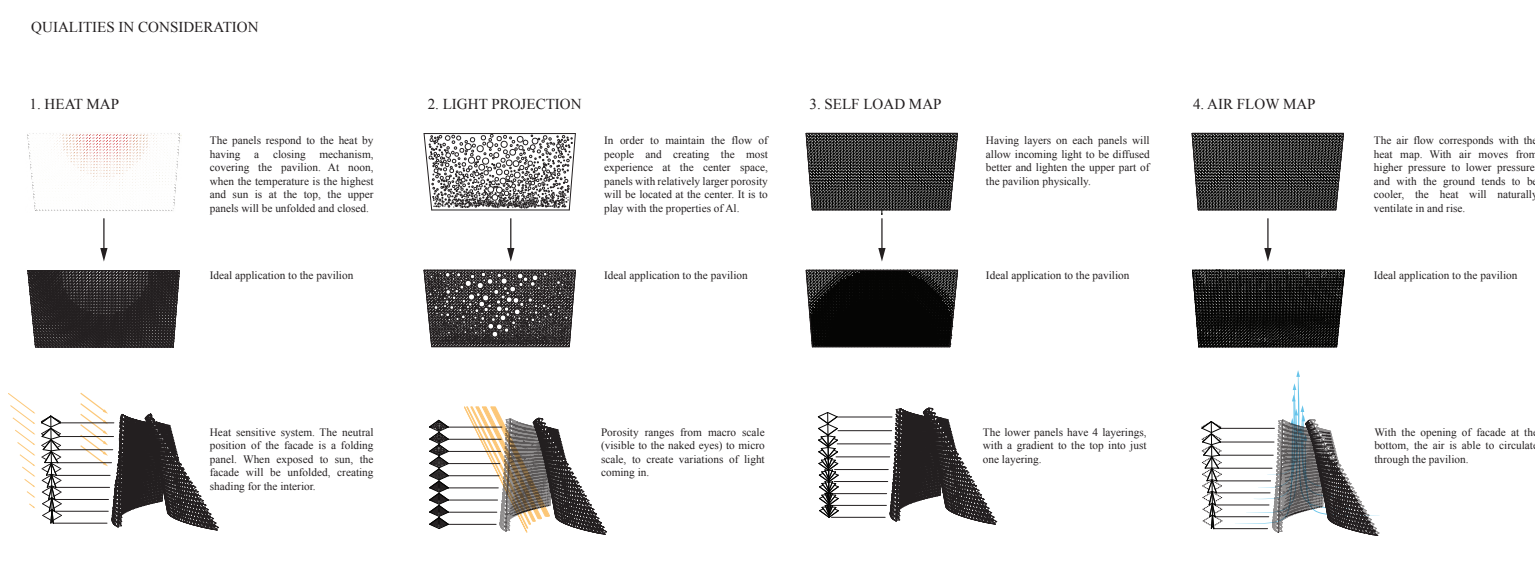

W
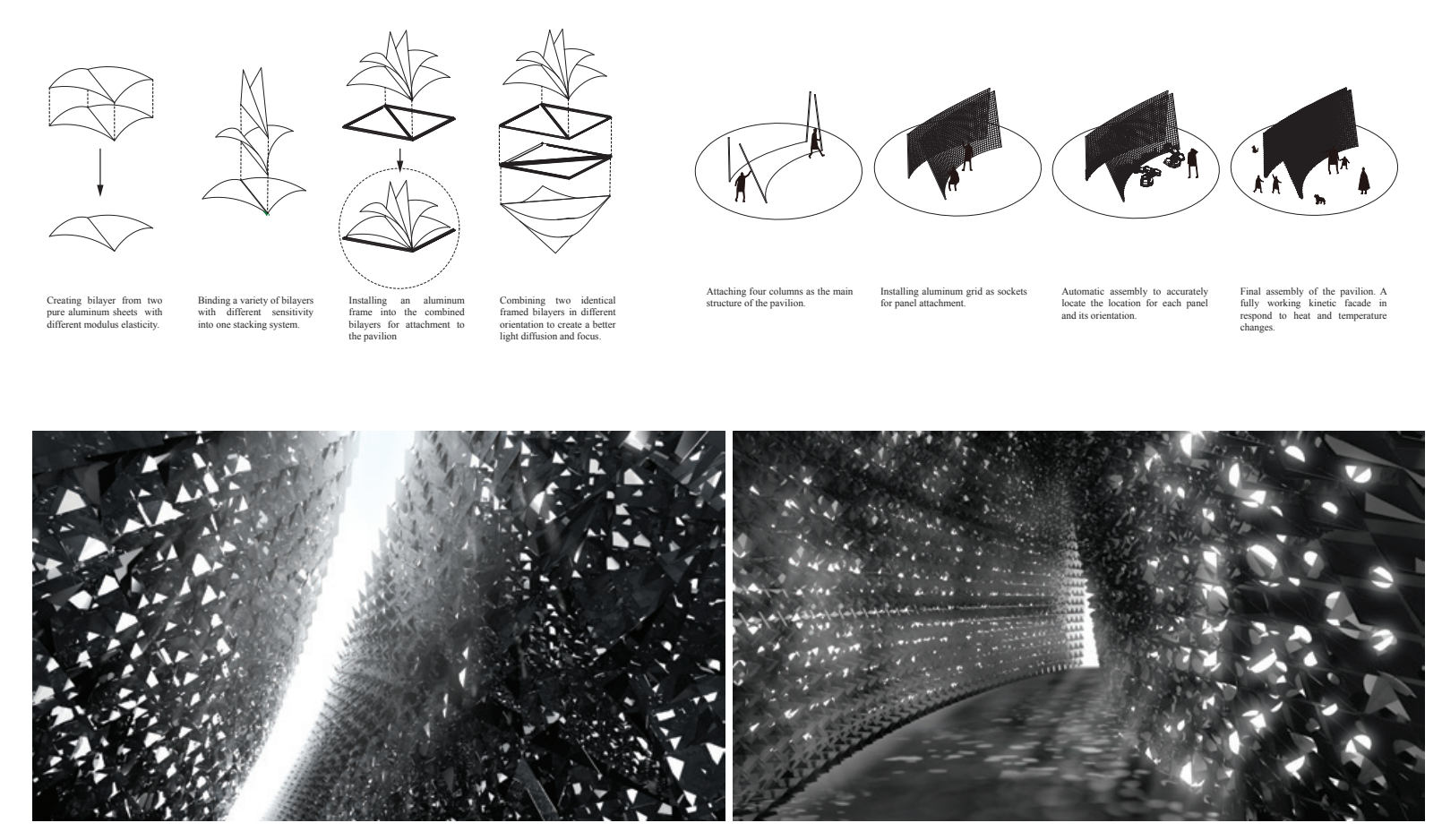

Fabrication Methods of Aluminum:

A.Materal Preparation:
storgae
aluminum needs to be ke

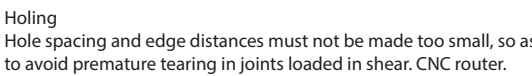

Forming
Using heat to bend and form aluminum

Machining

B. Mechanical Joints:
Boltitgand screving
close-fiting, in reamed

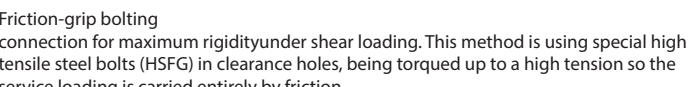

giveting (out of fatel

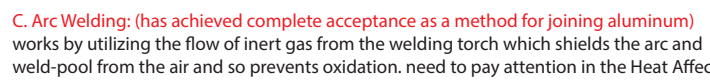

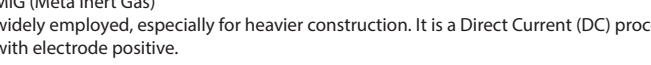

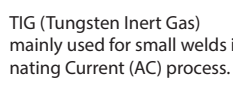

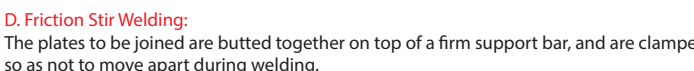

E.Aahesive Bonding:

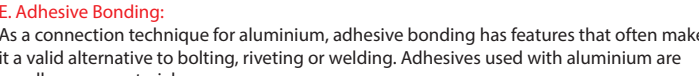

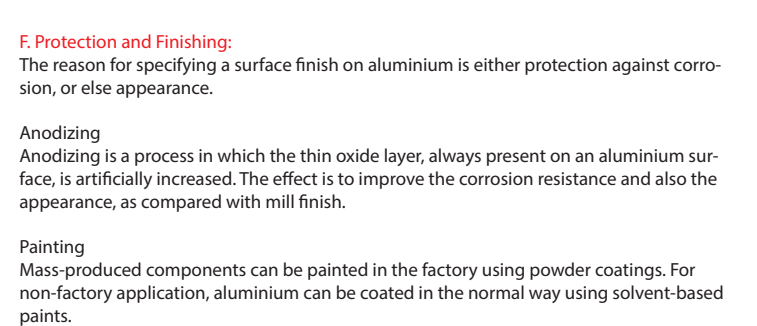

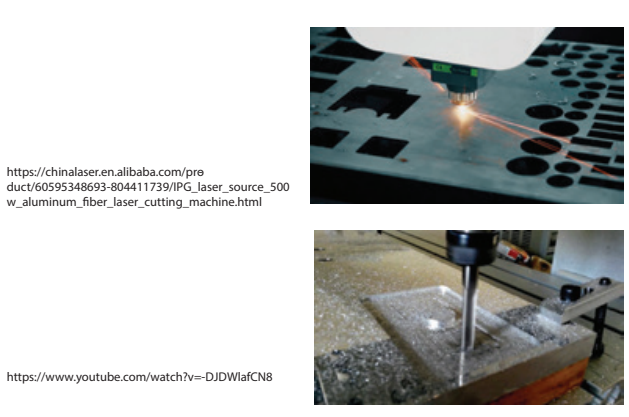
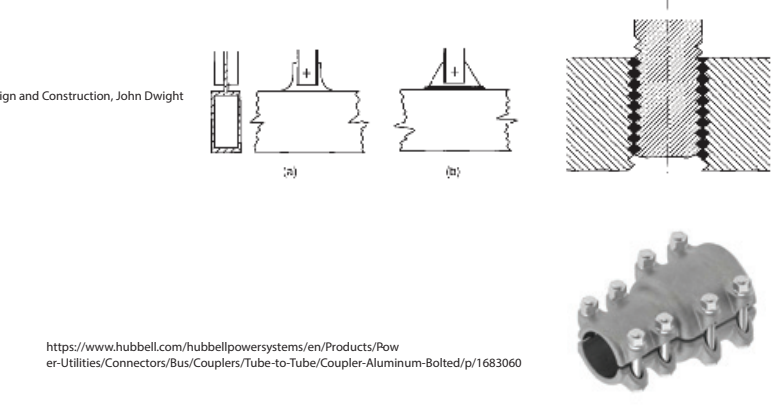

SPR $\rightarrow$
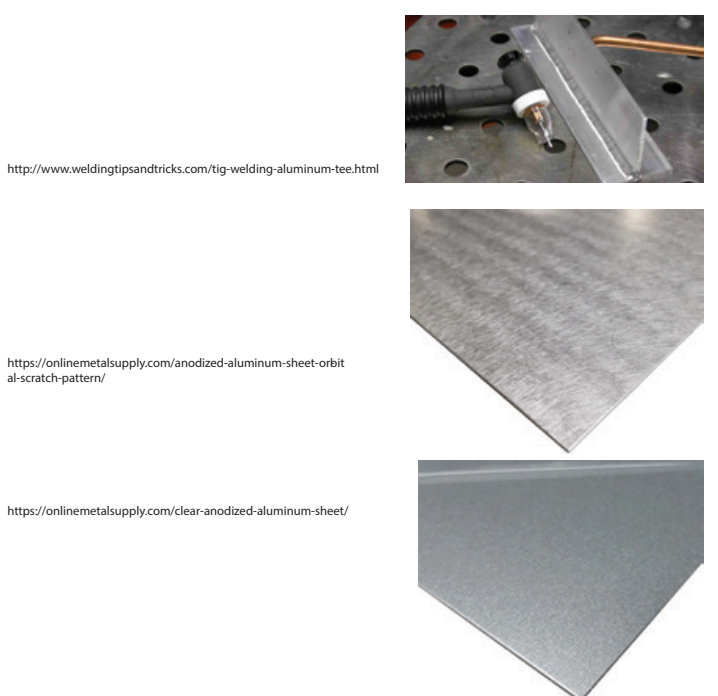

Material (aluminum) investigation and innovation 

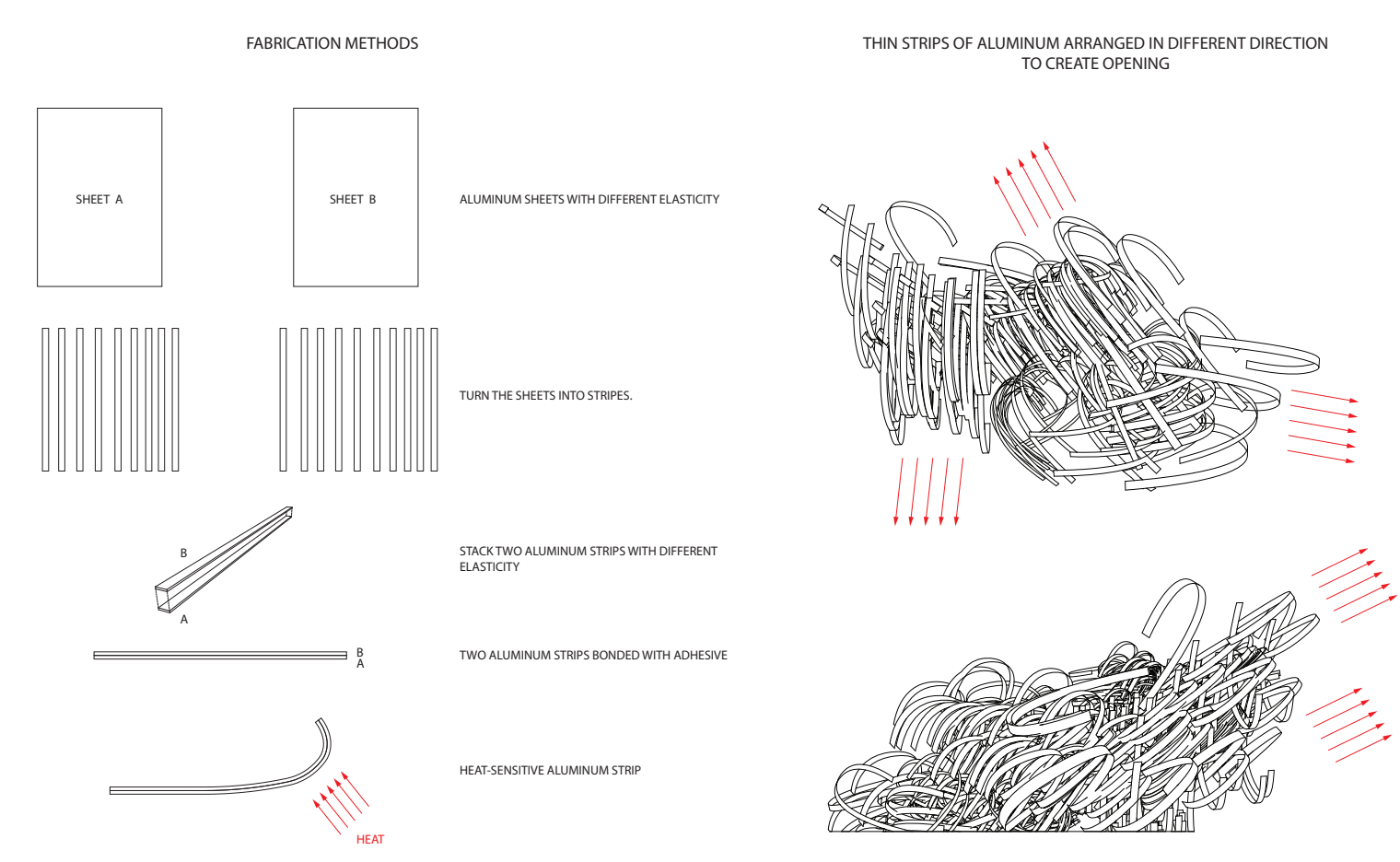

$$
\text { 麗 }
$$

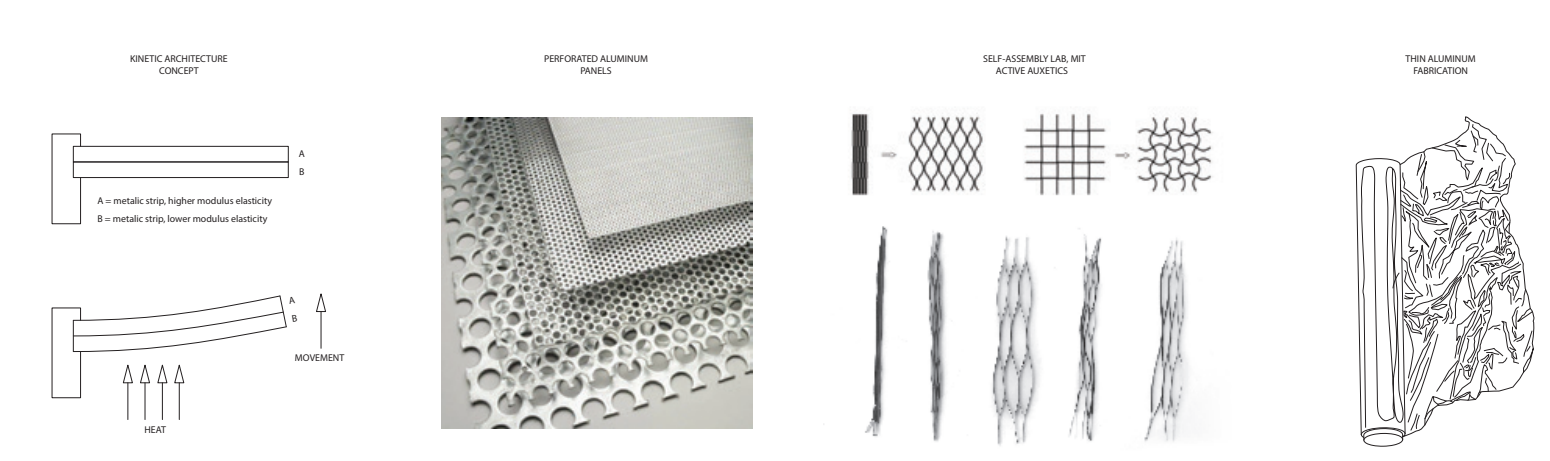

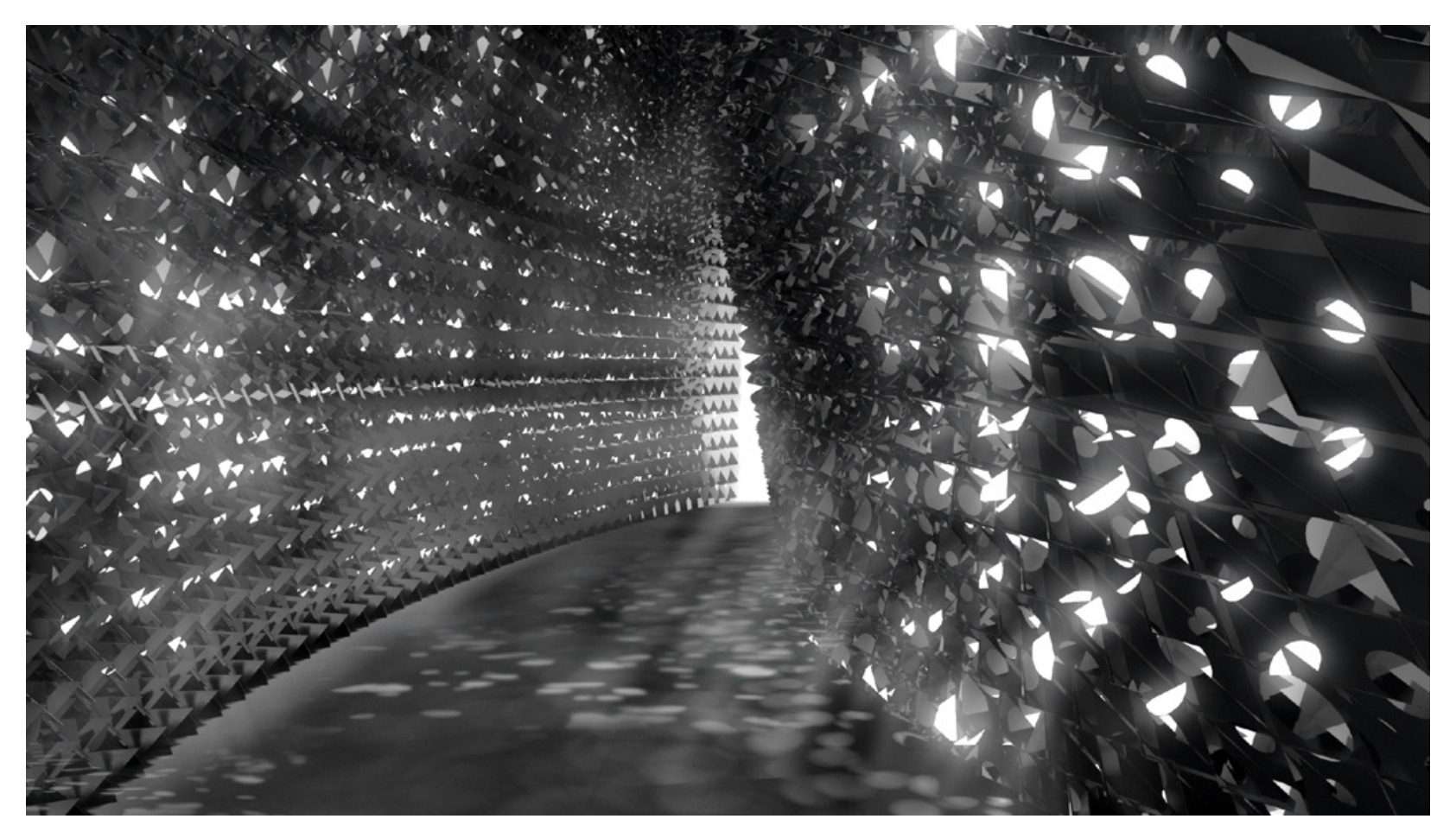

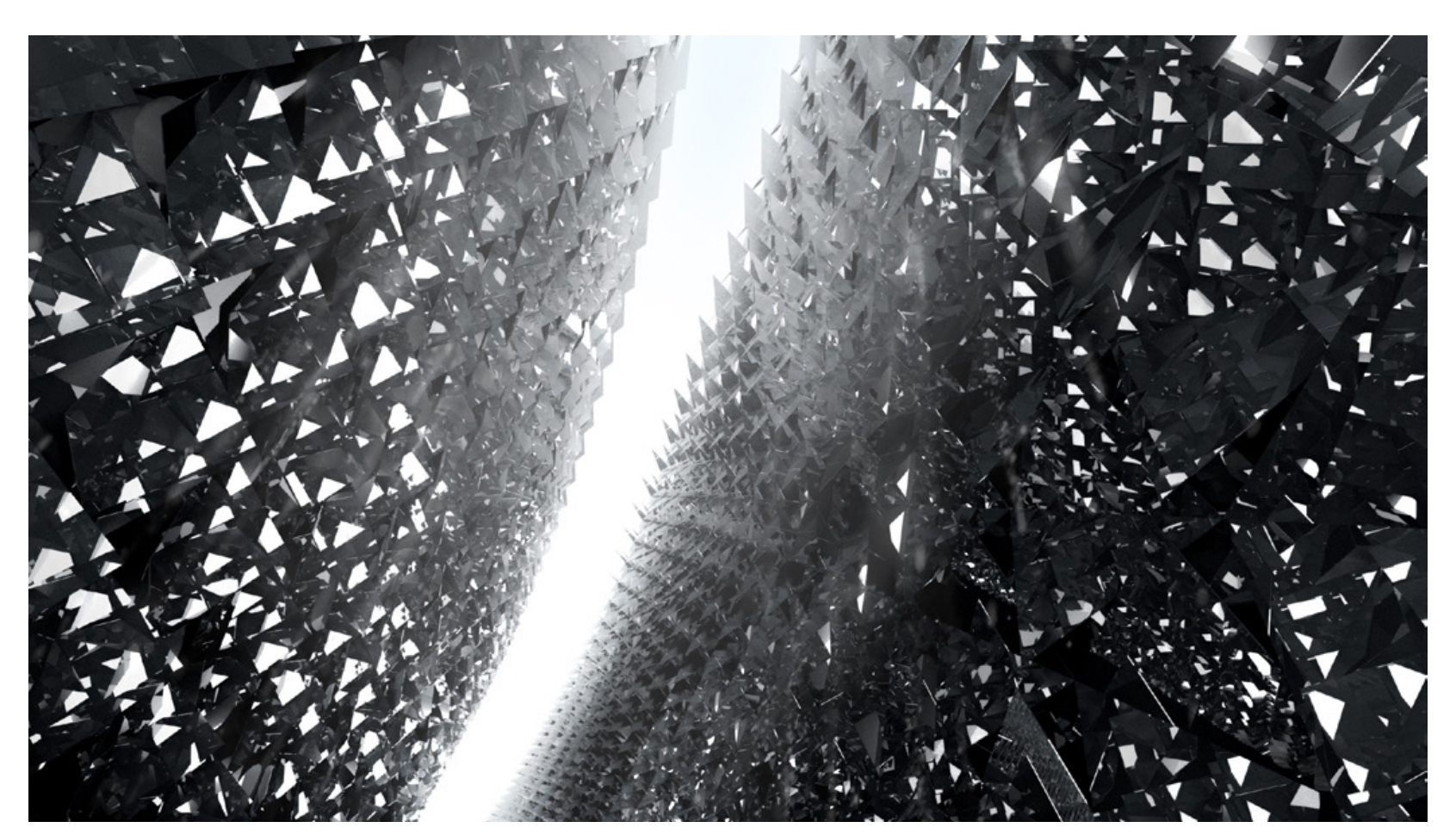




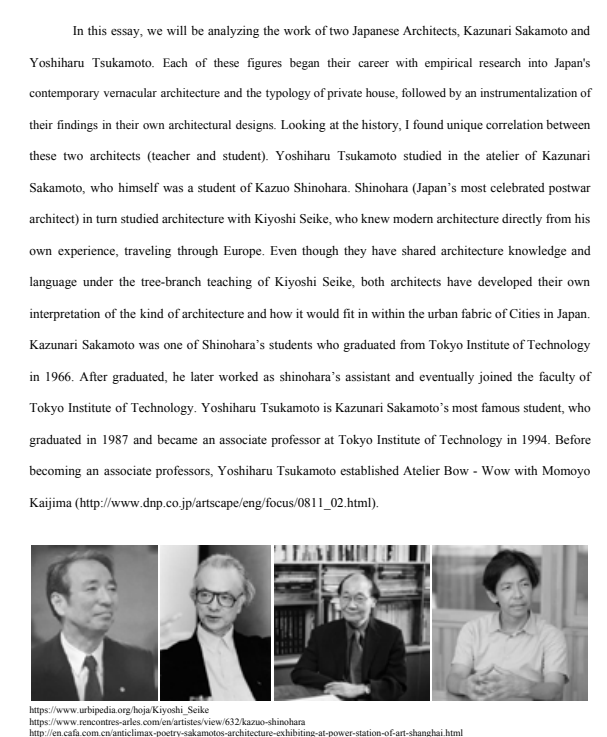

01

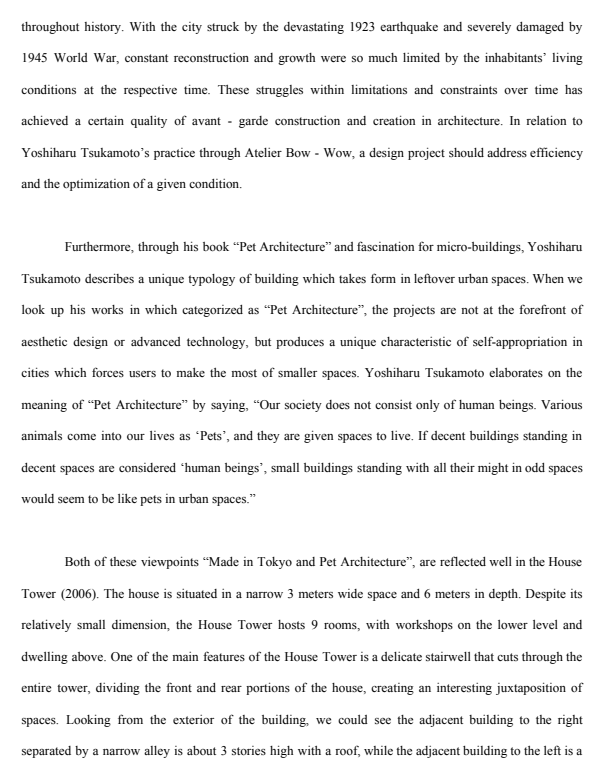
03
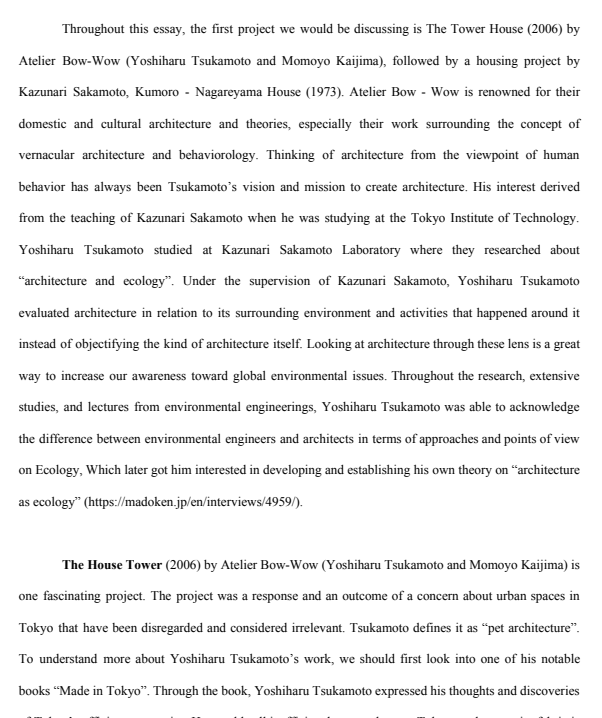

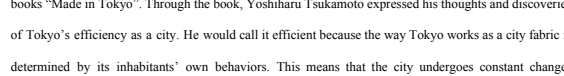
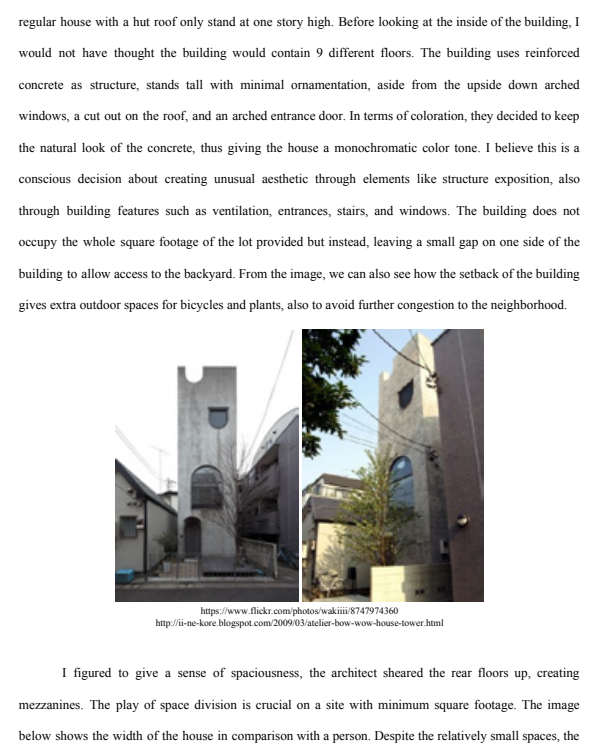

04
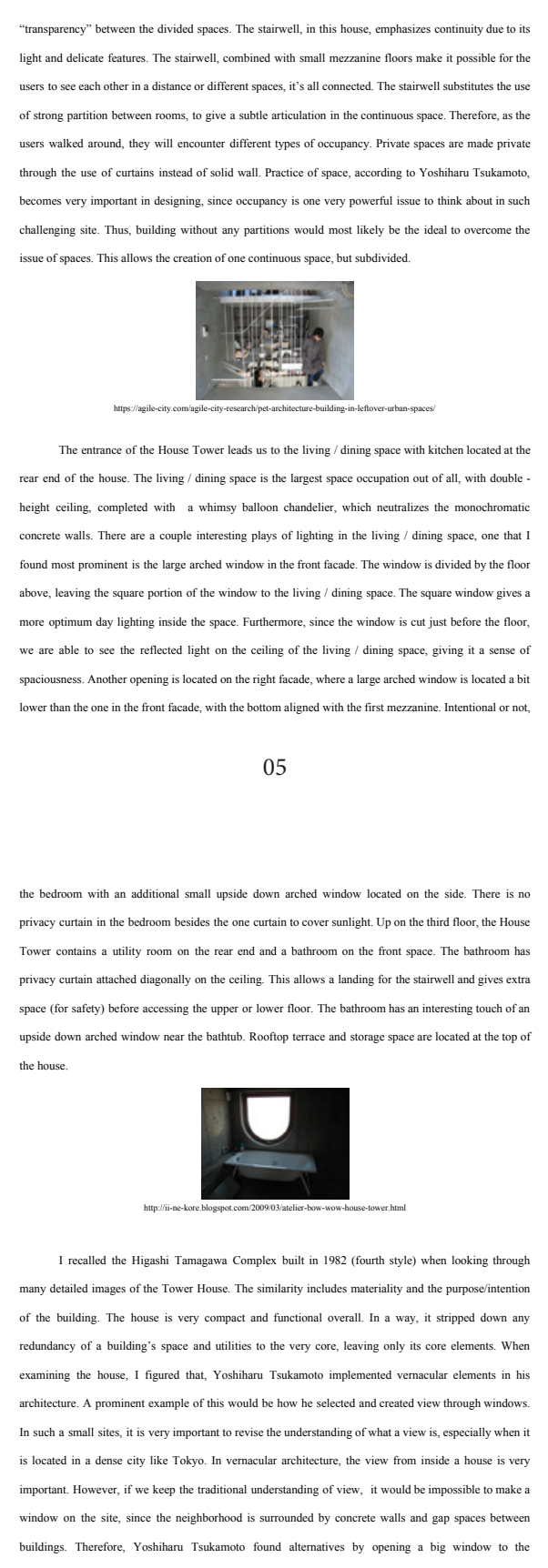

07

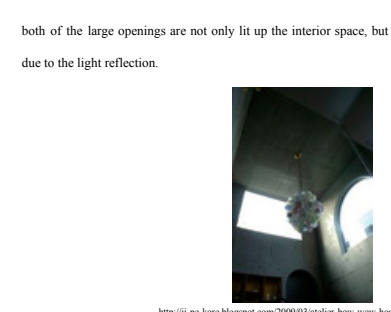

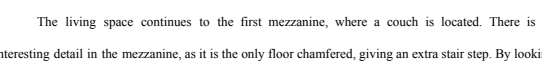

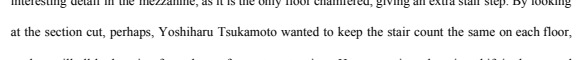

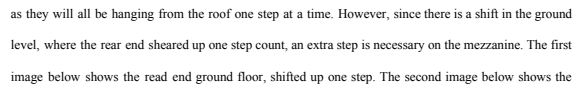

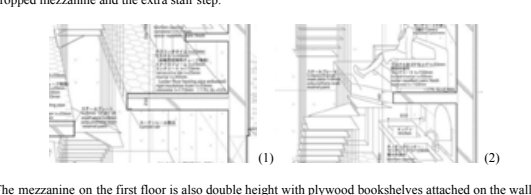

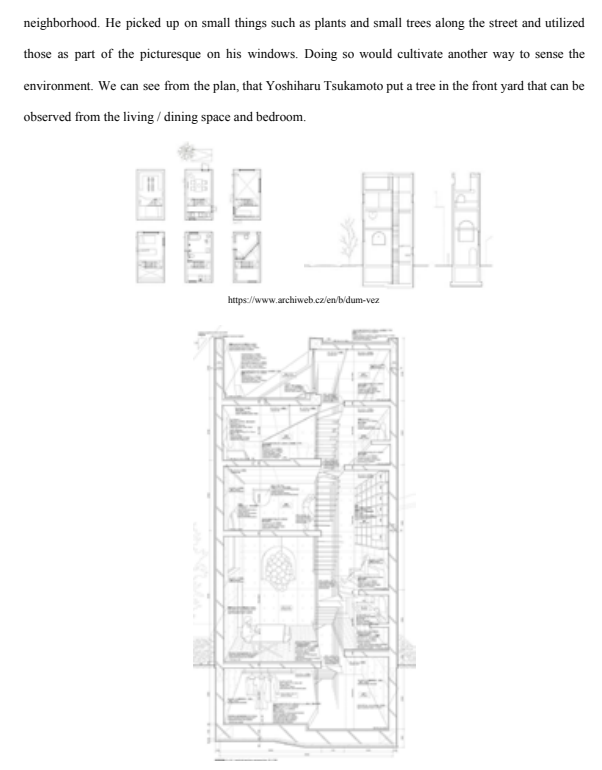

08

Research paper on Historical Architecture Typology and Japanese Architects 


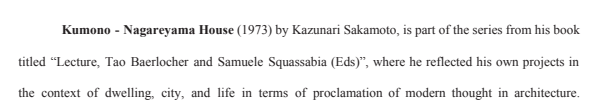

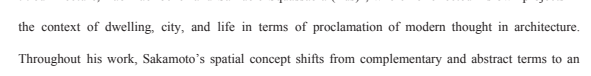

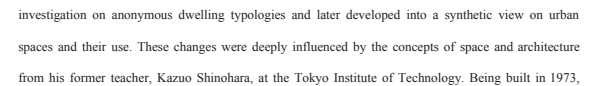

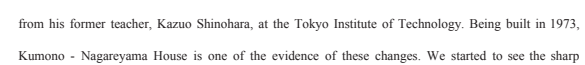

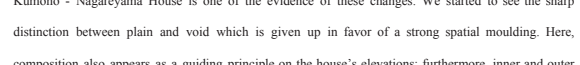

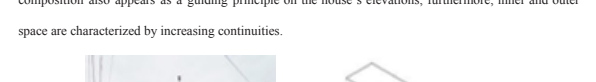

\section{Non}

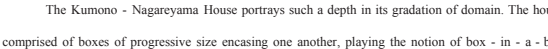

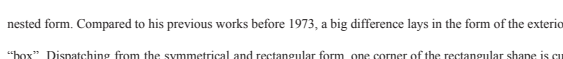

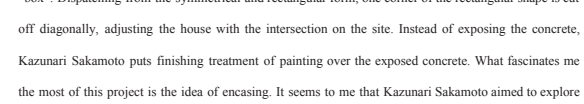
09

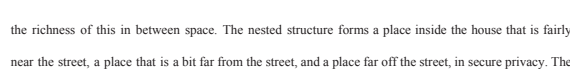

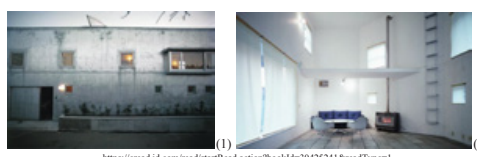

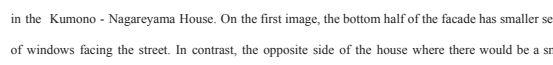

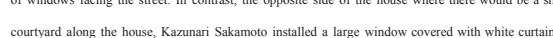

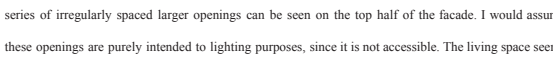

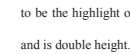

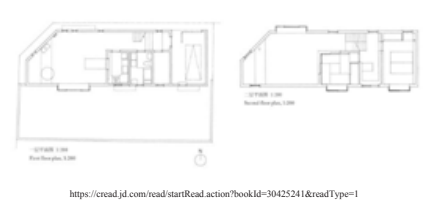$$
10
$$

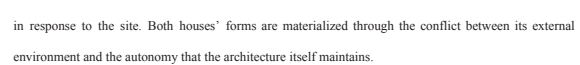

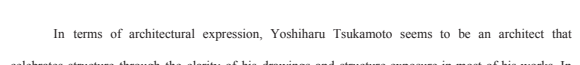

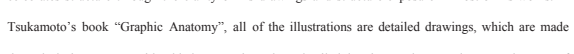

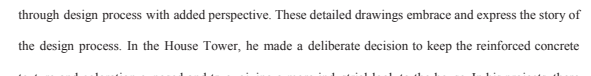

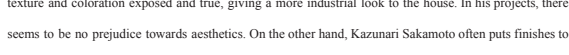

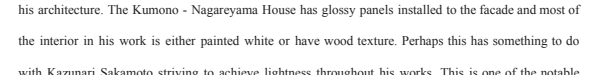

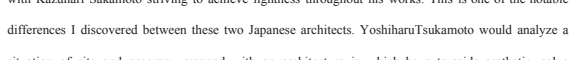

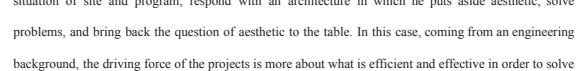

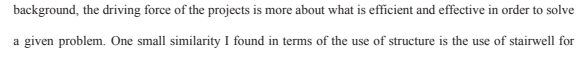

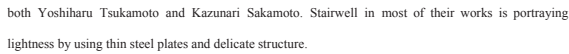

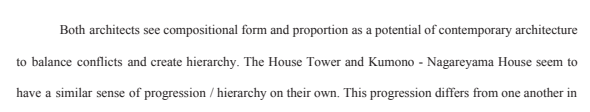

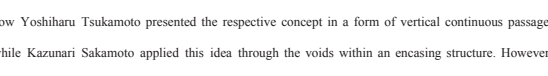

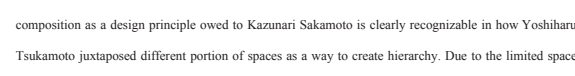

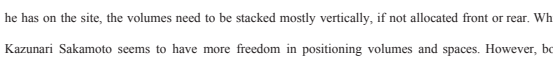

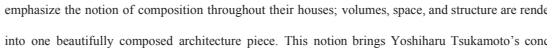

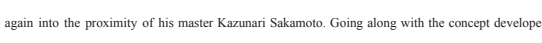

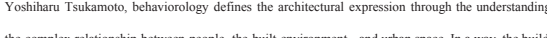

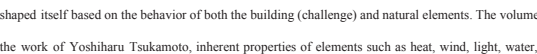

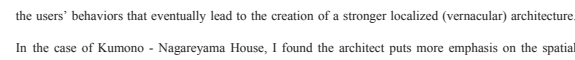

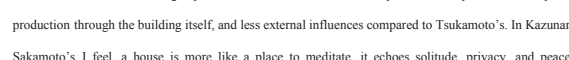

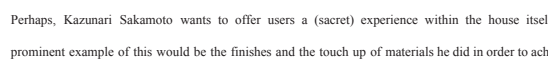

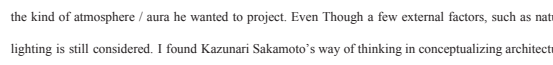

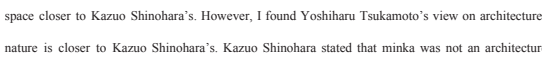

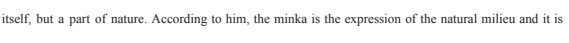

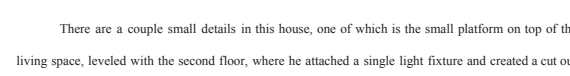

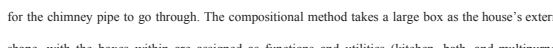

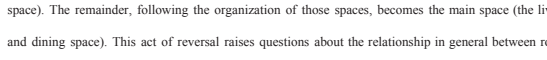

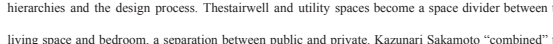

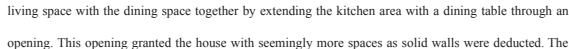

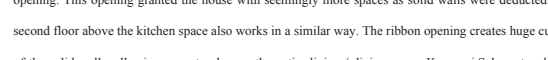

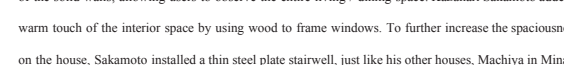

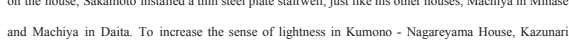
in

13

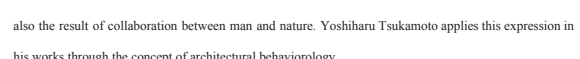

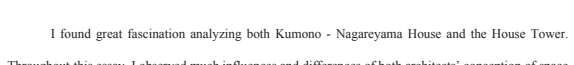

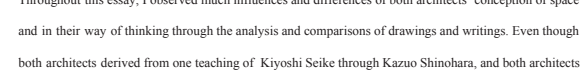

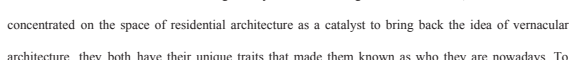

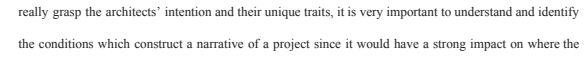

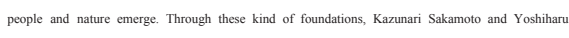

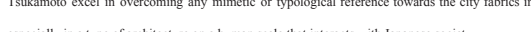

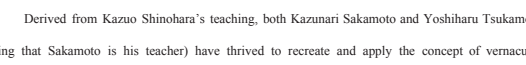

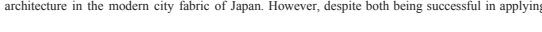

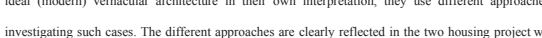

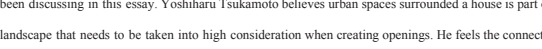
operings a s avy

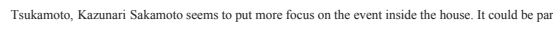

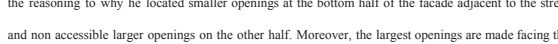

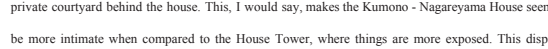

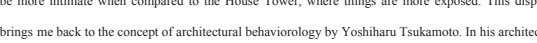

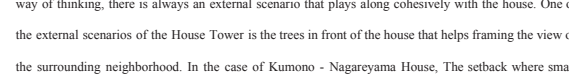

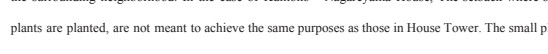

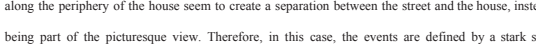

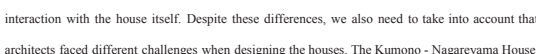

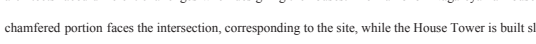

14

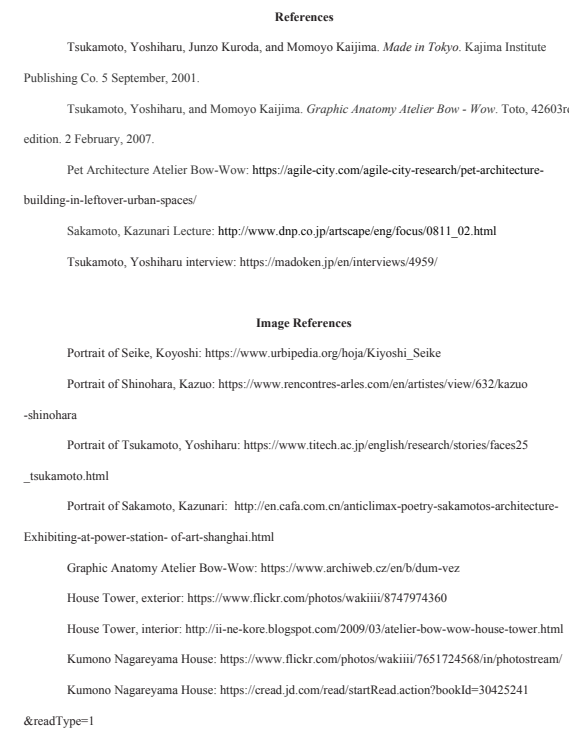

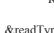


ARCH 6309 - Principles, Theories, and Elements in Japanese Architecture and Gardens Instructor : Leonard Jay Mirin

Work Type : Presentation Slides

Spring 2020
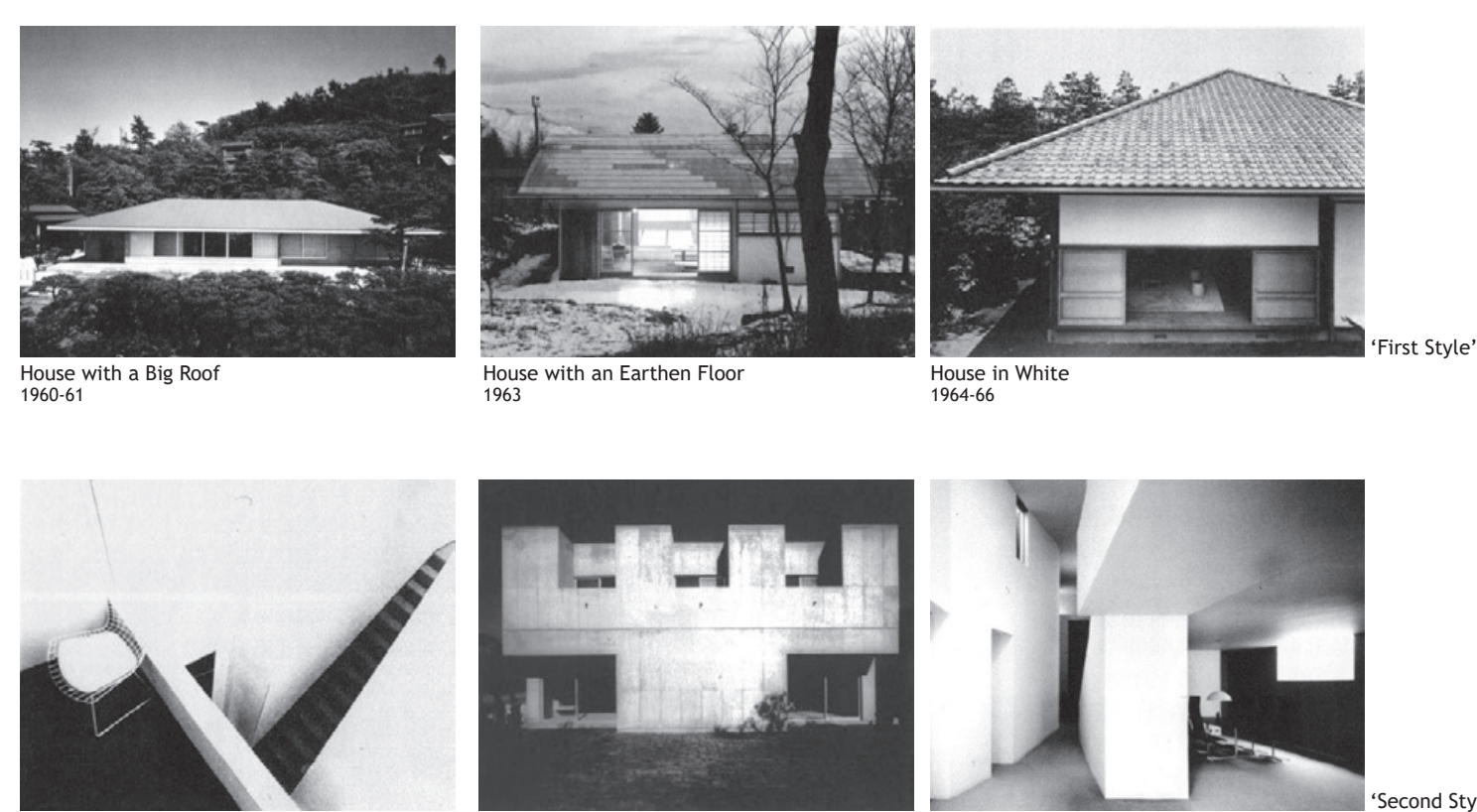

Repeating crevice
$1999 \cdot 71$

House in Kugahara
$1971-12$

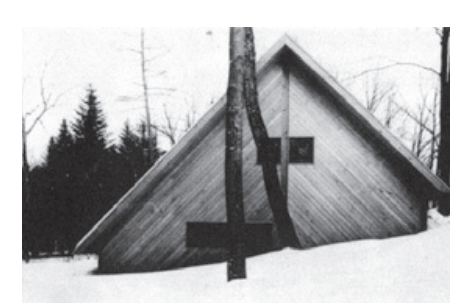

Tanikawa House
$1972-74$
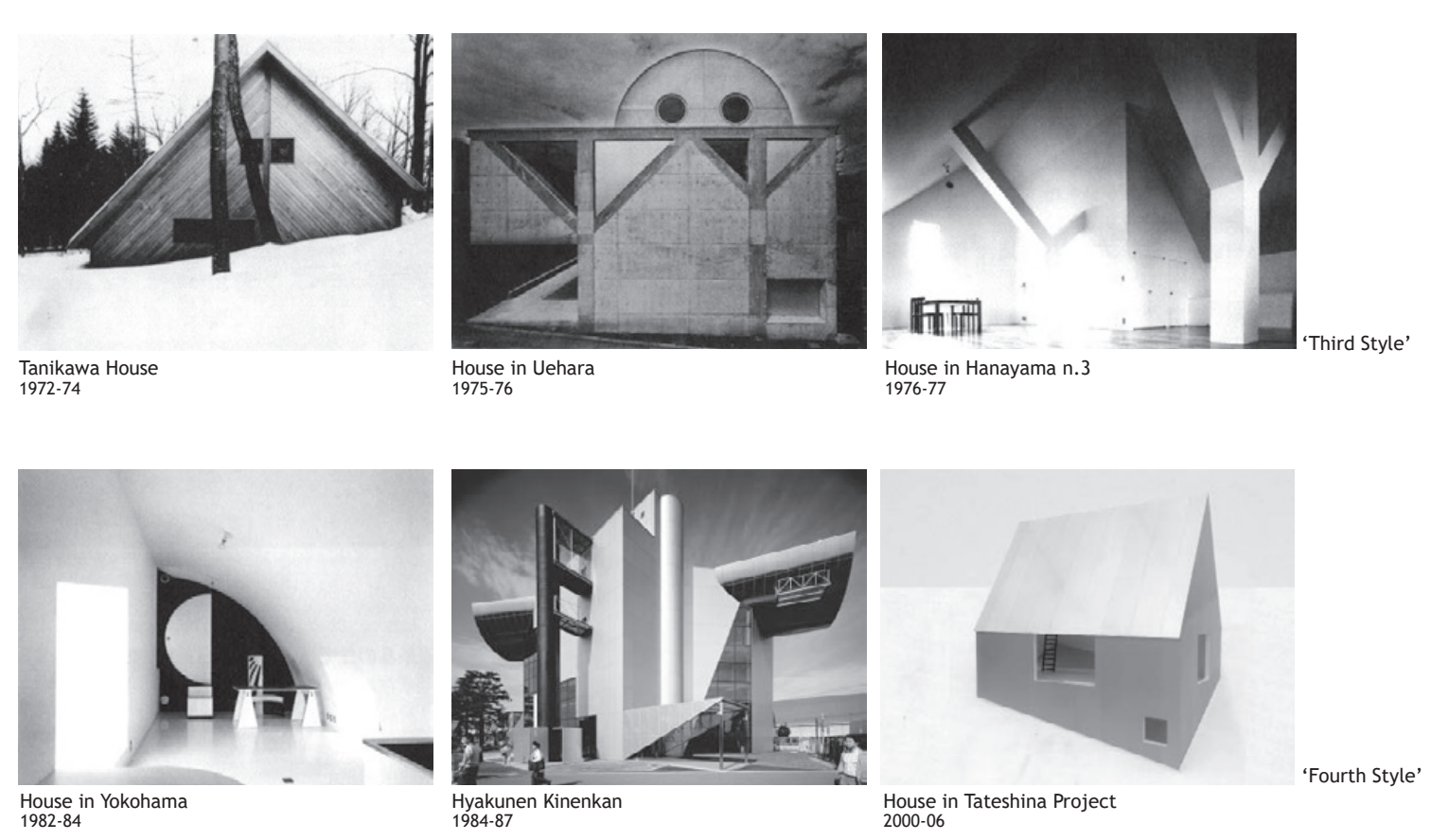

Comprehensive study on Kazuo Shinohara’s four architecture styles
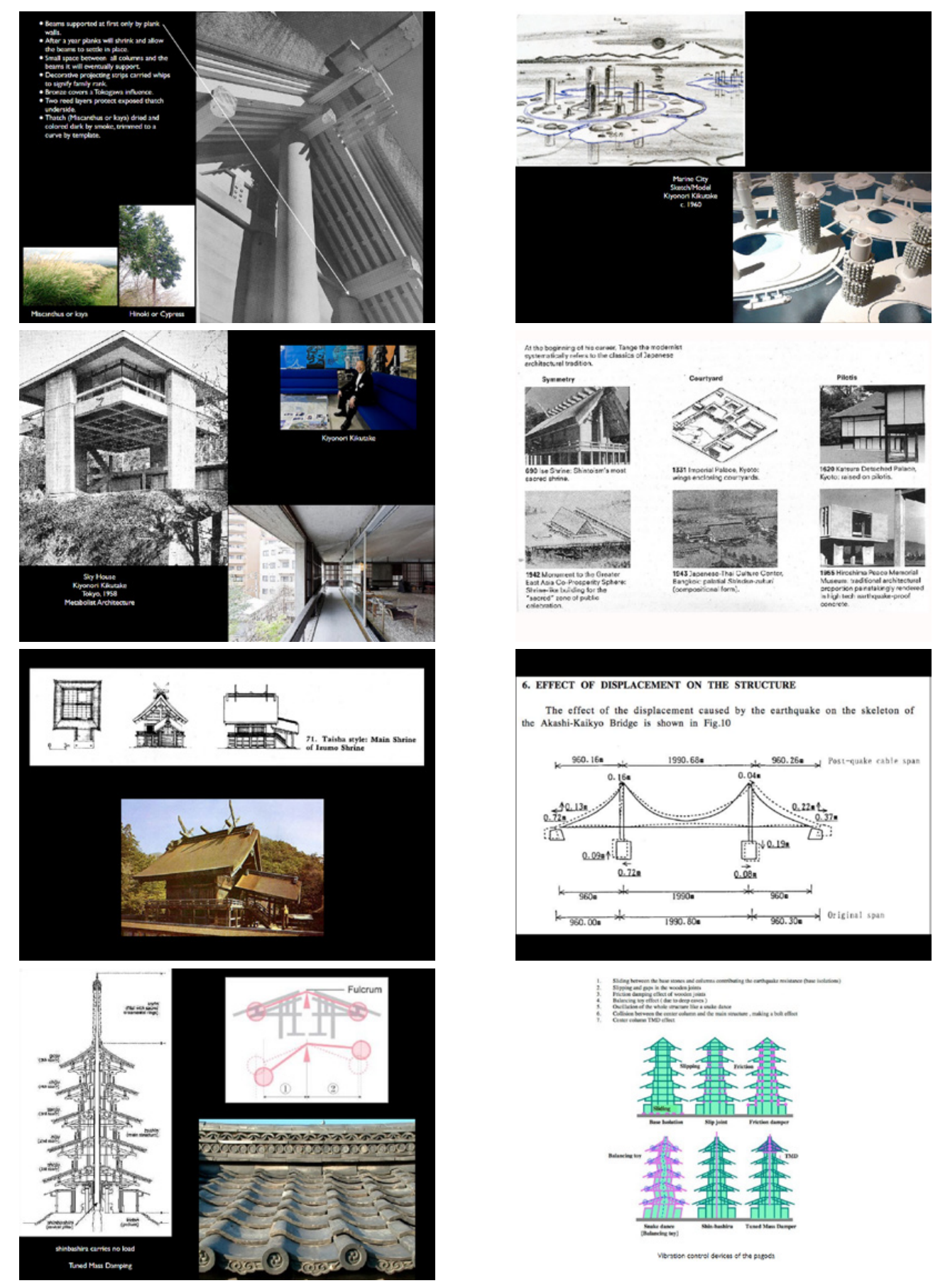

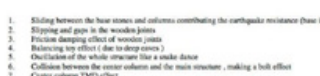

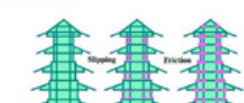

一全金企

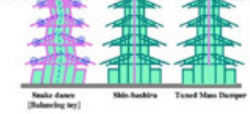

Comparative study of structural composition between the past and 